OPEN ACCESS

Edited by:

Fernando Manuel Pimentel-Santos,

Universidade NOVA de

Lisboa, Portugal

Reviewed by:

Antonio Ferrante,

South Australia Pathology, Australia

Herman Tam,

University of Alberta, Canada

*Correspondence:

Miroslav Harjacek

mharjacek@uaeu.ac.ae

Specialty section:

This article was submitted to

Rheumatology,

a section of the journal

Frontiers in Medicine

Received: 27 April 2021 Accepted: 06 September 2021

Published: 06 October 2021

Citation:

Harjacek M (2021) Immunopathophysiology of Juvenile Spondyloarthritis (jSpA): The "Out of the Box" View on Epigenetics,

Neuroendocrine Pathways and Role of the Macrophage Migration Inhibitory Factor (MIF). Front. Med. 8:700982.

doi: 10.3389/fmed.2021.700982

\section{Immunopathophysiology of Juvenile Spondyloarthritis (jSpA): The "Out of the Box" View on Epigenetics, Neuroendocrine Pathways and Role of the Macrophage Migration Inhibitory Factor (MIF)}

\section{Miroslav Harjacek*}

Department of Pediatrics, College of Medicine and Health Sciences, United Arab Emirates University, Al Ain, United Arab Emirates

Juvenile spondyloarthritis (jSpA) is a an umbrella term for heterogeneous group of related seronegative inflammatory disorders sharing common symptoms. Although it mainly affects children and adolescents, it often remains active during adulthood. Genetic and environmental factors are involved in its occurrence, although the exact underlying immunopathophysiology remains incompletely elucidated. Accumulated evidence suggests that, in affected patients, subclinical gut inflammation caused by intestinal dysbiosis, is pivotal to the future development of synovial-entheseal complex inflammation. While the predominant role of IL17/23 axis, TNF- $\alpha$, and IL-7 in the pathophysiology of SpA, including jSpA, is firmly established, the role of the cytokine macrophage migration inhibitory factor (MIF) is generally overlooked. The purpose of this review is to discuss and emphasize the role of epigenetics, neuroendocrine pathways and the hypothalamic-pituitary (HPA) axis, and to propose a novel hypothesis of the role of decreased NLRP3 gene expression and possibly MIF in the early phases of jSpA development. The decreased NLRP3 gene expression in the latter, due to hypomethylation of promotor site, is (one of) the cause for inflammasome malfunction leading to gut dysbiosis observed in patients with early jSpA. In addition, we highlight the role of MIF in the complex innate, adaptive cellular and main effector cytokine network, Finally, since treatment of advanced bone pathology in SpA remains an unmet clinical need, I suggest possible new drug targets with the aim to ultimately improve treatment efficacy and long-term outcome of jSpA patients.

Keywords: juvenile spondyloarthritis, enthesitis-related arthritis, pathophysiology, epigenetics, neuroendocrine pathways, hypothalamic-pituitary axis, gut-joint axis, macrophage migration inhibitory factor 


\section{LITERATURE SEARCH}

A systematic literature search was conducted in Ovid Medline (PubMed), Scopus, Science Citation Index expanded, and Google Scholar to find related articles. The key words were "juvenile spondyloarthirtis", "enthesitis-related arthritis (ERA)", "pathophysiology", "signal transduction”, "epigenetics", "neuroendocrine pathways", "stress response”, "HPA axis”, "sex hormones", "gene expression”, "proteomics”, “Gut-joint axis”, "dysbiosis" "NLRP3", "tissue hypoxia", "new bone formation $(\mathrm{NBF})$ " in combination with "macrophage migration inhibitory factor (MIF)". I also manually screened the reference lists in relevant reviews and other non-primary data sources captured by the search strategy. Only publications in English were included.

\section{INTRODUCTION}

Spondyloarthritis (SpA) is an umbrella term for a group of chronic inflammatory disorders that share common clinical and pathophysiological features. In children, enthesitis-related arthritis (ErA) is a subgroup of juvenile idiopathic arthritis (JIA) clinically characterized by enthesitis, chronic inflammatory arthritis, acute anterior uveitis, back pain, and low-grade gut inflammation. ErA also falls under the collective term of juvenile spondyloarthritis (jSpA) (1). Depending on the geographic region, ErA accounts for 15-30\% JIA cases and is one of the commonest subtype of JIA seen in Asia (2). The jSpA commonly starts as "undifferentiated" disease (e.g., ERA) which differs between children and adults. For example, in juvenileonset disease (jSpA), when compared to adults, hip arthritis is more frequently observed, there is a lower prevalence of human leukocyte antigen B27 positivity, axial involvement and acute anterior uveitis, but less peripheral arthritis and enthesitis (1). Although several classification criteria are used in children for uniformity of diagnoses, several other conditions share similar clinical features, thus resulting in either overlap or indistinct classifications. The juvenile spondyloarthritis (JSpA) is a perfect example of that, as the currently available criteria do not reflect their complexity and peculiarities (3).

The SpA family of diseases comprises undifferentiated jSpA (ERA), ankylosing spondylitis (AS), reactive arthritis (ReA), psoriatic arthritis (PsA), and inflammatory bowel disease (IBD) associated arthritis. In general, SpAs are depicted by inflammation, bone erosions and new bone formation (NBF). Enthesis, representing the connective tissue junction where ligaments and tendons attach to the bone, is a primary target tissue for inflammation in SpA, with inflammation affecting both the enthesis soft tissue and the nearby anchoring peri-entheseal bone (PEB) (4). In fact, the anchoring PEB, or synovial-entheseal complex, is the main site of inflammation and osteitis in SpA (5).

As expected, the majority of the published genetic studies in $\mathrm{SpA}$ have been restricted to ankylosing spondylitis (AS), the classical form of $\mathrm{SpA}$ in adults. The genetic heritability of juvenile spondyloarthropathy remains incompletely understood, with HLA-B27 accounting for almost $25 \%$ of its identified heritability, with newly discovered gene mutations responsible for $2.1 \%$ of inherited cases (6). However, studies have shown that
HLA-B27 positivity on its own is not sufficient to trigger disease as the concordance rate for HLA-B27 positivity in dizygotic twins was shown to be significantly lower than for monozygotic twins (24 vs. 63\%, respectively), suggesting the important role of other relevant genes with an oligogenic model of familial transmission (7).

\section{GENE EXPRESSION AND PROTEOMIC STUDIES}

Recent genome-wide association studies (GWAS) and single nucleotide polymorphisms (SNPs) analysis have further delineated the role of non-MHC genes in the development of adult AS, involving the interaction of endoplasmic reticulum aminopeptidase 1 (ERAP1) with HLA-B27 (8). The role of ERAP1 was also later confirmed for ErA and IL-23R for juvenile psoriatic arthritis (9). ERAP1 polymorphisms only affect the risk of development of SpA in HLA-B27-positive individuals, suggesting that they influence SpA pathogenesis by altering HLA-B27 function (10). Nevertheless, for better understanding of differences between genotype and phenotype as well as mechanisms of disease development, research methods such as quantification of gene expression are often necessary. So far, although a number of different gene expression studies in adult patients have been conducted, they included only a small number of patients with jSpA (11-13). In another cohort of patients diagnosed with ErA, using ILAR criteria, and with a known HLA genotype, none of the transcriptome studies was performed with RNA isolated from whole blood, nor was the calculation of the odds ratio (OR) for disease development performed, with absence of independent verification of data specificity and universality. Our group conducted a meticulous gene expression analysis in a very homogenous group of Croatian patients with enthesitis-related arthritis (ErA) diagnosed according to ILAR classification criteria. We documented increased expression of TLR4 and CXCR4 and decreased expression of NLRP3 and PTPN12 genes (13). In another ErA cohort from the USA, Barnes et al., found different genes or gene clusters, resulting in the under-expression of hemoglobin genes, with unknown significance so far (11). In a different study by Myles et al. involving Indian patients with ErA, gene expression in synovial fluid mononuclear cells (SFMCs) was compared to that in peripheral blood mononuclear cell (PMBCs). SFMCs were found to have a different gene expression profile from PBMCs, with overexpression of genes associated with various cell processes such as antigen presentation, scavenger function, chemotaxis and proteases, while genes involved in NK cell function, cell adhesion and inhibitors of apoptosis were under-expressed, suggesting a dysregulation of the innate immune system genes in that condition (12). The mechanism(s) responsible for those alterations, which differ among populations, remain largely unknown (see below).

Gene expression studies provide important information about the involvement of various signal pathways. They rely, however, on plasma which is frequently used as surrogate, instead of the synovial membrane proteome, actual site of pathology, from 
early disease-stage, which would be most informative for precise determination of immunopathology of $\mathrm{jSpA}$. However, synovial membrane is extremely difficult to acquire. Although control tissue from healthy children would have been useful, ethical considerations prevent it. On the other hand, as synovial fluid $(\mathrm{SF})$ is in close proximity to tissues primarily altered during jSpA, analyzing it has significant potential to better understand the underlying immunopathogeneses. In the study of Rozenkranz et al. distinctively 24 proteins were identified as differentially abundant in SF between JIA subtypes, but jSpA patients were not included (drugi link). However, in the Taiwanese pilot study of two children with diagnosed enthesitis-related arthritis (ERA), the patients' plasma was studied before and after the administration of etanercept alone, using conventional twodimensional gel electrophoresis (2-DE) in combination with mass spectrometry (MALDI-MS). They showed that etanercept therapy improved clinical ERA symptoms through the regulation of several cytokines (IL-2/IFN- $\gamma$ ), chemokines (MCP-1), and growth factors (GRO) that affect the expression of specific acute phase proteins such as haptoglobins, immunoglobulin A, and fibrinogen- $\gamma$ chain (14). However, there are many challenges within the SF proteomics field including the requirement for standardized and stringent methods of sample collection and storage, the differences in sensitivity and specificity of various proteomic assays, the impossibility of including healthy controls, compounded by the lack of comprehensive biostatistical analysis of the data to exclude falsely detected biomarkers (15).

\section{EPIGENETIC STUDIES}

The role of epigenetic mechanisms is essential in the regulation of gene expression, and consequently in the pathogenesis of various diseases, including rheumatic conditions $(16,17)$. The notion that these mechanisms could be influenced by external stimuli raises the possibility of a link between the environment and gene function, providing a potential clue for the potential contribution of these external stimuli to many diseases. Epigenetic mechanisms are traditionally defined as mitotically and/or meiotically heritable changes in gene expression that do not involve changes in DNA sequence. To contribute to the control of gene expression and repression, they are closely connected with other regulatory elements, such are transcription factors, and in some cases, with extracellular factors such as cytokines and growth factors (17). Although various studies have already confirmed the prevalence of epigenetic changes in both genetically complex and monogenic inflammatory rheumatic diseases, such are rheumatoid arthritis (RA), systemic lupus erythematosus (SLE), systemic sclerosis (SSc), Sjorgen syndrome (SS), Cryopyrin-associated periodic syndrome (CAPS) and Familial Mediterranean Fever (FMF), to best of our knowledge, none has looked at patients with juvenile spodyloarthritis (1619). In oligo-JIA, Chavez-Valencia et al. have found no substantial alterations in DNA methylation of $\mathrm{CD}^{+}{ }^{+} \mathrm{T}$ cells, but only modest alterations in genes of known or potential relevance to JIA (20). On the other hand, DNA methylation of the pro-inflammatory interleukin-32 (IL-32) gene was found to be reduced in JIA
$\mathrm{CD} 4+\mathrm{T}$ cells, suggesting an association between the reduction of IL-32 methylation and JIA (21). At present, there are at least three accepted mechanisms that can initiate and maintain epigenetic alterations: DNA methylation as pretranscriptional, histone modifications and non-coding RNA (ncRNA)-associated gene silencing like microRNAs (miRs) at the posttranscriptional level $(22,23)$. In our recent study in patients with ErA, we assessed the methylation levels of the TLR4, CXCR4, NLRP3, and PTPN12 gene promoter, as well as the expression of several noncoding microRNAs (miR-150, miR-146a, miR-181a and miR223) with reported interactions with the specific genes we were interested in. We collected PBMCs from 19 newly diagnosed patients with $\mathrm{jSpA}$, according to ILAR classification criteria for enthesitis-related arthritis (ErA), and seven gender- and agematched asymptomatic children. Out of four genes studied, we only found hypermethylated NLRP3 gene, while the expression analysis of selected microRNAs showed no significant difference $(24,25)$. DNA methylation studies in adults with AS have already identified over 1600 hypermethylated loci in the peripheral blood, most of which are located in HLA genes (26). In other studies, genes such as DNMT1 and BCL11B were found to be hypermethylated, but their expression did not correlate with the clinical manifestations of ankylosing spondylitis $(27,28)$. In a similar study of patients with AS, Coit et al. demonstrated an overexpression of hypermethylated genes like GTPase-related genes, as well as hypomethylated genes that included HCP5 gene encoding a lncRNA within the MHC region linked with a genetic risk for psoriasis and toxic epidermal necrolysis. Furthermore, the presence of an HLA-B*27 allele was associated with strong hypomethylation of HCP5, tubulin folding cofactor A (TBCA) and phospholipase D Family Member 6 (PLD6), of unknown relevance at this point (29). On the other hand, the miRNA expression profiles in the blood of patients with AS showed 19 differentially expressed miRNAs, with increased levels of miR-146a and miR-155 compared to controls, and with the disease index correlating only with miR-155 expression (30). Furthermore, IL-10 inhibits the pro-inflammatory microRNA miR-155 through STAT3 (31). This is relevant in the context of SpA where generally low IL-10 values are found in patients across the different phenotypes (see below).

\section{STRESSORS EXPOSURE AND NEUROENDOCRINE IMMUNO-MODULATION}

When environmental strains exceed the human adaptive capacity or ability to cope, stress will occur. These environmental strains are collectively termed stressors, and appropriate responsiveness of the stress system to stressors translates into a sense of general wellbeing, adequate task performance and positive social interactions (e.g., homeostasis) $(32,33)$. By contrast, the effect of various stressors may hamper a child's growth and development, and may be responsible for various rheumatology, endocrine, metabolic, immune-mediated and psychiatric disorders (33). For example, in the extensive Swedish cohort of 2,453 adults with AS, increased risk for disease development was linked to 
respiratory tract infections in childhood (34). As shown in both adult and pediatric patients with rheumatological conditions, the occurrence of stressful or traumatic life events frequently precede the onset of their illness or disease flares. It is well known that trauma or mechanical stress are frequent triggers or flareinducers of JIA, and particularly for the induction of enthesitis (35). Moreover, stress can cause the brain to trigger the immune response, which can, in turn, induce changes in the central nervous system (CNS) suggesting bidirectional communication. However, in the course of chronic inflammation, an interruption of this communication might be possible.

Based on the observation of sex differences in AS, in studies performed over 50 years ago an etiological association with endocrine factors was suggested. A study of testicular function in 22 patients with AS demonstrated diminished testicular testosterone $(\mathrm{T})$ reserve, elevated luteinizing hormone (LH) serum level, estradiol/testosterone ratio (E2: T) inversion and slightly increased estradiol (E2) serum level $(36,37)$. Interestingly, in the animal SKG mouse model (SpA model), estrogen was found to suppress TNF- $\alpha$ and arthritis development (38). Similarly, other animal model studies have shown that estrogen can suppress the differentiation of T helper (Th)17 cells from naive T cells (39).

Low serum levels of sex hormones, especially dehydroepiandrosterone sulfate (DHEAS) (i.e., androgen drain), may also contribute to bone loss in patients with AS, while patients with early or adult reactive arthritis have a high cortisol and DHEA serum levels that might change the course of disease $(40,41)$. After administration of a low-dose of adrenocorticotropic hormone (ACTH), the serum cortisol rise became significantly lower in patients with AS than in controls, suggesting an impaired hypothalamic-pituitary-adrenal (HPA) axis and reinforcing the possibility of involvement of the neuroendocrine system in the etiology of AS ("the disproportion principle") (42). More importantly, low cortisol and testosterone serum levels were found in subjects with active JIA, while the lowest androgen levels were found in those patients in whom disease extended into their adult life (43). In addition, Bravo et al. found elevated levels of serum prolactin (PRL), another pro-inflammatory hormone, in male patients with juvenile ankylosing spondylitis, with levels correlating with disease activity (44). The detailed description of the neuroendocrine pathways including HPA, arousal/sympathetic nervous system (SNS) and parasympathetic nervous system (PNS), are beyond the scope of this paper but have been detailed in other reviews (45-51).

The role of the HPA axis extends to the glucocorticoid (GC) metabolism. Cortisol is converted to cortisone mainly by the kidney, via $11 \beta$-hydroxysteroid dehydrogenase (11 $\beta$-HSD) type 2 , while the major organ for converting cortisone back to cortisol is the liver, via $11 \beta$-HSD1. Interestingly, in arthritis, conversion from cortisone to cortisol by $11 \beta-H S D 1$ is increased (48). In addition, the circadian rhythm of the HPA axis may be defective in overcoming the signs and symptoms of the disease associated with inadequate cortisol secretion. This may augment negative feedback and explain the HPA dysfunction in inflammatory conditions (49). On the other hand, macrophage migration inhibitory factor (MIF) is secreted from identical corticotrophic pituitary cell type know to secrete ACTH, the hormone that stimulates the adrenal secretion of glucocorticoids. MIF was shown in vivo to neutralize the glucocorticoidinduced suppression of inflammatory cytokine secretion in activated macrophages (i.e. TNF- $\alpha$, IL- $1-\beta$, IL-6, IL-8) (Figure 1) (52). The circadian variation in plasma MIF closely parallels glucocorticoid levels. During stressful events or life-threatening infections coupled with high levels of glucocorticoids, the antagonistic effects of MIF on glucocorticoids probably represent the mechanism by which the host preserves a functioning immune response (52). Ralph et al. provided evidence that described the nuclear orphan receptor 1 (NURR1) as a target of MIF and GCs in RA, and a repressor of MAPK phosphatase 1(MKP1) expression. MKP1, the negative regulator of MAPK activation has been identified as a key gene that regulates MIF. Thus, NURR1, target of both GCs and MIF in mediating their opposing effects on MKP1, appears to be involved in the vital regulatory network that influences both innate and adaptive immune responses, as well as disease phenotypes (53). There is therefore a clear transition from a well-functioning HPA axis in the early phases of undifferentiated spondyloarthritis or reactive arthritis, to an inhibited HPA axis in late stages of chronic spondyloarthritis. This phenomenon is thought to be due to proinflammatory cytokine production such as MIF, IL-6, TNF- $\alpha$ and IFN- $\gamma$, which are likely to negatively influence steroidogenesis. Thus, in chronic spondyloarthritis, MIF might counter-regulate the suppressive effect of glucocorticoids on cytokine mRNA translation (Figure 1).

The combination of reduced parasympathetic with increased sympathetic tone, has been a consistent finding in chronic adult arthritis patients, suggesting an imbalanced autonomic nervous system (53-56). The sympathetic nervous system (SNS) has a bimodal effect in the chronic arthritis, by either increasing or decreasing serum levels of proinflammatory and antiinflammatory cytokines. This depends on several factors, such as the time point of immune system activation, the cellular context, and the distinct adrenoceptors involved ( $\alpha$ vs. $\beta$ ) (54). Although there is no published evidence in juvenile spondyloarthritis, the peripheral blood mononuclear cells (PBMC) of adult patients with JIA express mRNA-encoding $\alpha$-adrenergic 1 receptors ( $\alpha 1$-AR subtype), which are not found in healthy children. It seems, therefore, that the expression of $\alpha 1-\mathrm{AR}$ mRNA in PBMC during chronic inflammation might be associated with attenuated immune responses to stress (57). Functional $\alpha 1$-AR receptors seem to be upregulated on the leukocytes of patients with poliJIA, resulting in higher IL-6 levels upon stimulation of these receptors by a cold pressor test (58). Consequently, the $\alpha$-ARs might become more relevant in a later stage of chronic inflammation, concurring with decreased numbers of $\beta$-ARs (" $\beta$ to- $\boldsymbol{\alpha}$-adrenergic shift”) (59). The endogenous synergy of HPA axis (cortisol) and SNS is clearly demonstrated in patients with chronic synovitis, by the stiffness and/or the decrease of high cytokine levels in the morning (47).

On the other hand, the immunosuppressive effect of the parasympathetic nervous system is much more obvious. The cholinergic anti-inflammatory pathway (e.g., 


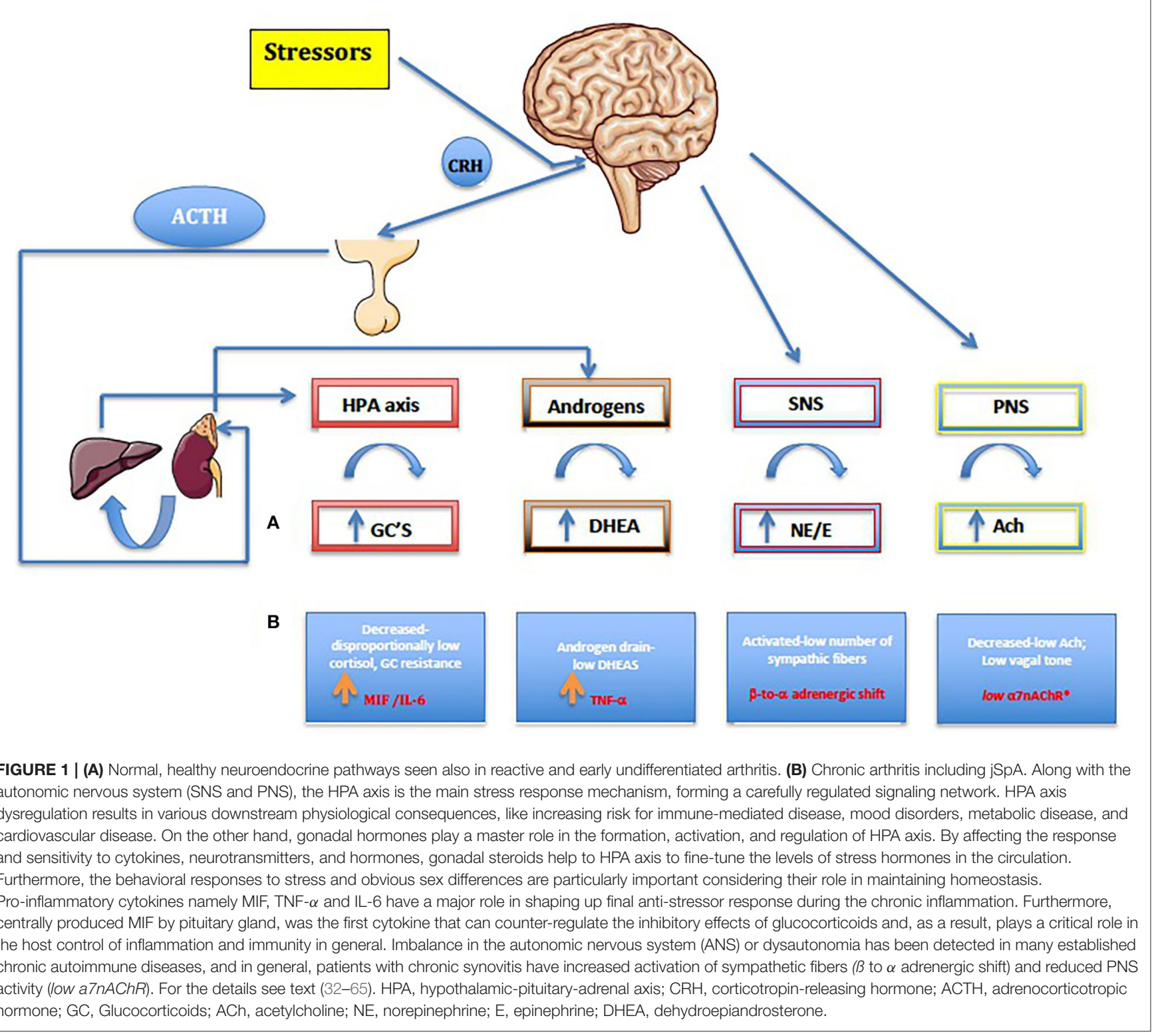

“anti-inflammatory reflex") can suppress inflammation through release of acetylcholine (ACh) by the vagus nerve, involving the alpha7 nicotinic acetylcholine receptor (alpha7nAChR) expressed on CD68+ macrophages and other immune cells (60-62). As a result, a series of well-known proinflammatory molecules such as TNF- $\alpha$, IL-6, MIF, IFN- $\gamma$, high-mobility group box-1 (HMGB-1), free radicals, inducible nitric oxide (iNO), and others are inhibited (61). Interestingly, both the $\alpha 7 \mathrm{nAChR}$, ubiquitously expressed by $\mathrm{CD} 4^{+} \mathrm{T}$ lymphocytes, and the $\mathrm{nAChR}$ agonist nicotine, can inhibit the production of IL-17 in $\mathrm{CD}^{+}{ }^{+} \mathrm{T}$ cells in human peripheral blood (63). In various animal models, such as those for arthritis and colitis, nicotine has also been shown to have an anti-inflammatory effect by inhibiting the polarization to Th1/Th17 (64). This mechanism has been reinforced in a small pilot study of 37 adult patients with psoriatic arthritis or AS, where a transcutaneous vagal nerve stimulation (t-VNS) led to a significant reduction in ASAS scores (65).

\section{SUBCLINICAL GUT INFLAMMATION (GUT-JOINT AXIS)}

The gut epithelial barrier is a first line of defense against harmful microorganisms. Disruption of the epithelial layer puts gut microbes in direct contact with the host's immune cells, thereby activating an aberrant inflammatory response. It has been shown that prenatal and early life bacterial gut colonization is thought to play a paramount role in shaping the immune system. This is translated into the gain of basic functions such as immunotolerance of commensal microorganisms. Early life exposures have been linked to the development of inflammatory 
bowel disease (IBD) later in life. Infants born to mothers with IBD demonstrated enrichment in Gammaproteobacteria in their gut, often associated with intestinal inflammation, and also depletion in protective Bifidobacteria. Likewise, germ-free mice (GFM) inoculated with stools of third trimester IBD mother and of 90-day infants, showed a significant reduction in microbial diversity and fewer class-switched memory B cells and regulatory $\mathrm{T}$ cells in the colon (66). A study by Yatsuneko et al. suggests that gut microflora evolves toward a stable configuration by the age of 3 years (67). On the other hand, subclinical gut inflammation is a hallmark in all forms of juvenile spondyloarthritis and is associated with a high prevalence of inflammatory bowel disease (IBD) (66). The involvement of the gut-joint axis of inflammation in jSpA is strengthened by similarities in immunopathogenesis, and also by the clinical success of anti- TNF- $\alpha$ and IL-23 therapies in both IBD and in some forms of SpA (67). It is believed that inflammation in SpA originates in the gut and subsequently leads to joint inflammation. Both conditions share many genetic risk factors as well as changes in the composition of gut microbiota. Although conceptually attractive, some therapies targeting IL$17 \mathrm{~A}$ are efficacious in the joint but not vice versa, and the targeting of adhesion molecules such as $\alpha 4 \beta 7$ in IBD can lead to onset or flares of SpA (67). Recent studies in ethnically different patient populations, and especially in patients with HLA-B27, have demonstrated dysbiosis in patients with SpA (6876). Such dysbiosis is highly dependent on the host's genetic background and/or environment, implicating an "ecological model of dysbiosis", with the effects of a multitude of microbes contributing all to the aberrant immunopathogenesis (77). At the functional level, different inflammation-associated microbes exhibit common metabolic pathways, including the synthesis of short-chain fatty acids (SCFA) such as butyrate, steroid biosynthesis as well as bacterial motility (78). The synthesis of butyrate, which has anti-inflammatory effects, promotes the development of regulatory $\mathrm{T}$ cells and is generally decreased in patients with SpA (78). The metabolomics data, in addition to less convincing $16 \mathrm{~S}$ data, suggest differences in tryptophan metabolism in children with ErA, linked to the fecal microbiota, with a pro-inflammatory effect (79). Furthermore, as shown in early AS and HLA-B27 positive adults, dysbiosis and a leaky gut lead to adaptive immune activation associated with characteristic MRI phenotype of osteitis (80). Whether these changes are intrinsically inherent to the disease, or are a mere consequence of a more systemic inflammatory process that also involves the intestine it is not clear at this point. However, data from animal models and studies on relatives of patients with $\mathrm{SpA}$, strongly suggest that these changes indeed precede the onset of the disease (76). In a some rheumatic disease it is possible that the use of specific probiotics, as an adjuvant therapy, correct the dysbiosis, resulting in the overall clinical efficacy. Our preliminary data has shown that VSL-3 medical probiotic, with a proven role in IBD, can improve clinical symptoms and decrease disease activity in jSpA patients (81). On contrary, different proof-of-concept studies from India, showed no clinical or immunological benefit in patients with JIA-ERA, with VSL-3 probiotic use compared to the regular use of NSAIDs (82).

\section{THE ROLE OF MACROPHAGE MIGRATION INHIBITORY FACTOR (MIF)}

While the dominant role of IL17/23 axis, TNF- $\alpha$, and IL-7 in pathophysiology of SpA, including jSpA, is well established, the role of cytokine MIF has generally been overlooked (8389). The MIF is a critical upstream alarming-like mediator of innate immunity and inflammation. Under physiological conditions MIF circulates with serum concentrations between 2 and $6 \mathrm{ng} / \mathrm{ml}$, with a circadian rhythm correlating with plasma cortisol (90). As mentioned earlier, it plays a pivotal role in the neuroendocrine axis mediated tissue-specific damage mechanisms, by counteracting the immunoregulatory effects of glucocorticoids (GCs) (52, 90). Unlike other cytokines, MIF is intrinsically expressed and stored in intracellular granules of various immune cells such as T- and B- lymphocytes, monocytes, macrophages, dendritic cells (DCs), mast cells, neutrophils, basophils, endothelial cells, tissue macrophages, and certain parenchymal cells (91). In response to liposaccharides (LPS) and stress, MIF is released from preformed cytoplasmic pools of mainly macrophages and dendritic cells. It up-regulates the expression of pattern recognition receptors, induces synthesis of downstream inflammatory cytokines, including IL-1 $\beta$, IL-6, TNF- $\alpha$, IFN- $\gamma$, IL-17 and sustains the inflammatory responses by inducing recruitment of neutrophils, monocytes, macrophages and DCs and inhibiting their activation-induced apoptosis $(92,93)$. In order to regulate autophagy/mitophagy as well as glucose catabolism, MIF induces, in an autocrine or paracrine manner, enhancement of phagocytosis and an increase of the production of reactive oxygen species (ROS) and nitric oxide (NO) (94-96). In humans, MIF, a 114-amino-acid nonglycosylated peptide of $12.5 \mathrm{kDa}$, is encoded by a single gene located on chromosome 22q11.2m (92). Two distinct polymorphisms of MIF exist: $\operatorname{rs} 755622(-173 \mathrm{G}>\mathrm{C})$ and rs5844572 (- 794 CATT tandem repeat). They exist in linkage disequilibrium, and are associated, in different proportions, with various autoimmune diseases, such as SLE, systemic onset JIA, psoriasis and ulcerative colitis (97-100). Depending on the cellular context and disease state, MIF signaling is mediated by its receptors CXCR2, CXCR4 and/or CD74. The latter receptor alone mediates extracellular MIF binding, but MIF-induced MAPK signaling requires the co-expression of hyaluronan receptor CD44 leading to subsequent activation of proinflammatory transcription factor nuclear factor- $\kappa \beta$ (NF$\kappa \beta)$ (101). The noncognate binding of MIF to CXCR2 and CXCR4 is the molecular basis for MIF-triggered recruitment of monocytes and $\mathrm{T}$ cells (102). In $\mathrm{T}$ cells and fibroblasts activation of JNK signaling by MIF involves the upstream kinases PI3K and SRC and is dependent on CXCR4 and CD74 (101). Besides, MIF inhibits p53-mediated apoptosis in macrophage with the induction of increased cytoplasmic phospholipase A2 (PLA2), arachidonic acid, COX2 and PGE2, which maintains the macrophage pro-inflammatory function (102). Increased gene expression of CD74 occurs in inflamed and noninflamed colonic mucosa of IBD patients, and it is also a possible $\mathrm{T}$ cell antigen in SpA, eliciting Th1 and Th17 responses (103, 104). 
Intracellular MIF is involved in Toll-like receptor and inflammasome-mediated inflammatory responses. It upregulates Toll-like receptor 4 (TLR-4) expression, and consequently induces the release of proinflammatory cytokines such as TNF$\alpha$ and interleukin IL-12, known to play an important role in pathogenesis of SpA (105). Loss of MIF has been shown to suppress the LPS-induced release of TNF- $\alpha$ by downregulating TLR4 expression (105). In response to the stimulation by LPS and Gram-negative bacteria (canonical TLR4 activators), the MIF-deficient macrophages have reduced production of TNF$\alpha$ and IL-6, underlining a role for MIF in modulation of TLR4 downstream signaling pathways (106). We have already proposed that the Thr399Ile polymorphism of TLR4, found in variant carriers of Croatian patients with jSpA but undetectable in Indian patients, may be accountable for modified immune response to microbial infection $(107,108)$. MIF, via an interaction with JAB1/ CSN5, directly affects transcriptional activity of activator protein-1 (AP-1), a central regulator of several proinflammatory genes (109). This hints to a possibly interesting overlap between MIF and glucocorticoid mediated (GC) responses. An important mechanism of GC action is the ability to suppress AP-1- and NF- $\kappa \beta$-regulated genes, with steroid-resistant disease being often associated with increased AP-1 activity (110). Moreover, MIF is either directly involved in the assembly and activation of the NLRP3 inflammasome, or via intermediate filament protein vimentin, which is essential for NLRP3 activation (111). More importantly, this role is independent of its function as a cytokine, because recombinant and native MIF are unable to salvage NLRP3-dependent IL-1 release in $\mathrm{Mif}^{-/-}$macrophages (111). Depletion or inhibition of MIF in macrophages and DCs result in the inhibition of IL- $1 \alpha$, IL- $1 \beta$ and IL-18 in response to NLRP3-activating stimuli. It appears, therefore, that by regulating NLRP3 inflammasome activation and downstream IL-1 $\beta$ production, MIF has an upstream role in outlining the inflammatory characteristics of activated macrophages and DCs (111). Activation of caspase-1 is the main characteristic of inflammasome activation, with higher caspase-1 serum level in $\mathrm{SpA}$, gout, inflammatory arthritis, and osteoarthritis than in other conditions (112).

Moreover, hypoxia initiated by microbiotome, plays a physiologic role in the normal intestine, and has also a diseaseperpetuating role in the intestines of IBD patients (113). The oxygen used for butyrate metabolism is an important factor of intestinal homeostasis. Butyrate has a dual role: it is the primary fuel source for the colon, and also shapes the gut microbiotome (114). Hypoxia stabilizes hypoxia-inducible factor (HIF), a transcription factor that regulates many genes important for intestinal barrier function $(115,116)$. In addition, following a hypoxic stimulus, innate immune cells, including neutrophils, macrophages and dendritic cells, resist apoptosis, and in addition, intra-epithelial cells (IECs) are stimulated to produce TNF- $\alpha$ and other pro-inflammatory cytokines, causing increased barrier permeability (e.g., leaky gut) (117). This effect is furthermore perpetuated by oxygen consumption by the luminal bacteria, and also by inflammatory mediators and LPS, which also regulate HIF activity (117). The chronic HIF stimulation in the colon epithelial cells initiates a hyperinflammatory reaction and, at least in mice,
HIF- $1 \alpha$ enhances experimental colitis through a MIF-dependent inflammatory signaling cascade, reversed by MIF inhibition (118). This autoamplifying feedback loop could be interrupted by high doses of GCs via the GCR, or by the inhibition of HIF1 an expression/stabilization under normoxia (119). MIF-JAB1 interaction also stabilizes HIF $1 \alpha$ by preventing its hydroxylation, resulting in increased expression of pro-angiogenic factor such as VEGF $(120,121)$. These observations support the view that hypoxia is a key driving factor in chronic inflammation, and in case of jSpA on both gut and joint levels. Hypoxia, and in particular HIF-1 $\alpha$, are very potent inducers of MIF in the joints, as shown in cultured RA synovial fibroblasts stimulated by rhMIF (121). In macrophage cultures, hypoxia induces TLR-4 which is also important in the context of jSpA (122). Therefore, accumulating evidence supports hypoxia and HIFs in regulating a number of important pathophysiological characteristics of chronic arthritis, including synovial inflammation, angiogenesis, and cartilage destruction (123).

\section{SUGGESTED NOVEL HYPOTHESIS}

Following the above discussion, I suggest a novel hypothesis in which decreased NLRP3 gene expression, due to epigenetic modifications of promotor site, is (one of) the cause for inflammasome malfunction leading to gut microbiota composition alterations observed in patients with early jSpA. This dysbiosis (caused by NLRP3 dysfunction) could potentially cause increased influx of TLR4 ligands and increased expression of the TLR4 gene (possibly due to Thr399Ileu polymorphism of TLR4), reduction of commensal bacteria with anti-inflammatory properties, namely Faecalibacterium prausnitzii, known to inhibit NF- $\kappa \beta$ signaling, and finally leading to TNF- $\alpha$ abundancy, characteristic of jSpA (124).

The reduced expression of NLRP3 gene is a new and intriguing observation in jSpA/ErA. Studies on the role of NLRP3 inflammasome in IBD yielded controversial results. Earlier studies have reported that activated NLRP3 inflammasome stimulated production of IL-1 $\beta$ and IL-18 and contributed to intestinal inflammation (125). However, the concept of damaging inflammasome signaling in IBD is currently being reconsidered. This follows recent reports showing that IL-1 $\beta$ and IL-18 production can provide protection against colitis, and supported by recent GWAS studies showing that the polymorphisms which confer hypofunctional NLRP3 phenotypes are associated with the development of IBD (125). Note added in proof comes from the recent finding by Yao et al. who were using the gain of function NLRP3 R258W mice. They found that the hyperactive NLRP3 inflammasome, associated with local over-production of IL-1 $\beta$, could maintain gut homeostasis resulting in strong resistance to experimental colitis. It appears that remodeled gut microbiota and increased induction of regulatory $\mathrm{T}$ cells were main mechanisms responsible for observed resistance (126). Therefore, it seems that a defective NLRP3 inflammasome signaling in the gut contributes to IBD, causing leaky gut and the induction of harmful immune responses against invading commensals (127). 
I further speculate that hypermethylation of NLRP3 can be promoted by certain MIF genotypes, based on similar association of MIF rs755622C allele with hypermethylation of tumor suppressors $\mathrm{p} 14^{\mathrm{ARF}}$ and $\mathrm{p} 16^{\mathrm{INK} 4 \mathrm{a}}$, both encoded by Cyclin Dependent Kinase Inhibitor 2A (CDKN2A). Hypermethylation of both $\mathrm{p} 14^{\mathrm{ARF}}$ and $\mathrm{p} 16^{\mathrm{INK} 4 \mathrm{a}}$ was found in normal colonic mucosal tissues of patients with UC, as well in the precancerous lesions, suggesting that UC patients with this particular inflammatory genotype of MIF may be at a higher risk for developing colonic cancer (128). This rs755622C genotype association was also observed in patients with IBD and in Chinese patients with psoriasis, but not in Turkish patients with AS (97, 98, 129). Despite that, the authors have suggested that the time of onset and the duration of AS still might be affected by rs755622C allele (129). However, this hypothesis still needs to be proven in the laboratory, along with testing for MIF-rs755622C allele in more patients with early-onset jSpA. In summary, the downregulated NLRP3 gene in patients with early jSpA/ErA might reflect the occurrence of a subclinical inflammation of the gut mucosa ("low-grade IBD"), leading to a leaky gut (Figure 2).

While the role of MIF in the early phases of SpA development is still speculative, its role in the late phases of disease is well established. Earlier reports have shown that inflammatory markers and serum MIF levels were significantly higher, and antiinflammatory IL-10 levels were significantly lower, in patients with AS when compared to control patients. There is also a significant correlation between disease activity indices (BASFI) and MIF levels in these patients (130). It was therefore suggested that MIF may be involved in the pathogenesis of the chronic inflammation in AS. This was confirmed in a recent study where MIF was shown, not only to trigger inflammation, but also promote osteoblastic activity, suggesting its novel pathogenic role in new bone formation (NBF) in patients with $\mathrm{SpA}$. It is important to mention that in $\mathrm{SpA}, \mathrm{NBF}$ contributes to the disease burden independently of the pain and stiffness induced by chronic inflammation. In patients with AS increased levels of MIF have been demonstrated in the synovial fluid and ileum with a high number of MIF-producing macrophages and Paneth cells. Furthermore, increased MIF-induced TNF- $\alpha$ production was detected in monocytes and activated $\beta$-catenin in osteoblasts, both processes involved in promotion of the mineralization of osteoblasts leading to NBF causing spinal progression (131).

The level of expression of microRNA-451 was recently found to be lower in PMBCs of patients with AS, while MIF expression in PMBCs was significantly increased compared with those with $\mathrm{pSpA}$ and controls, indicating that MiR-451 suppresses

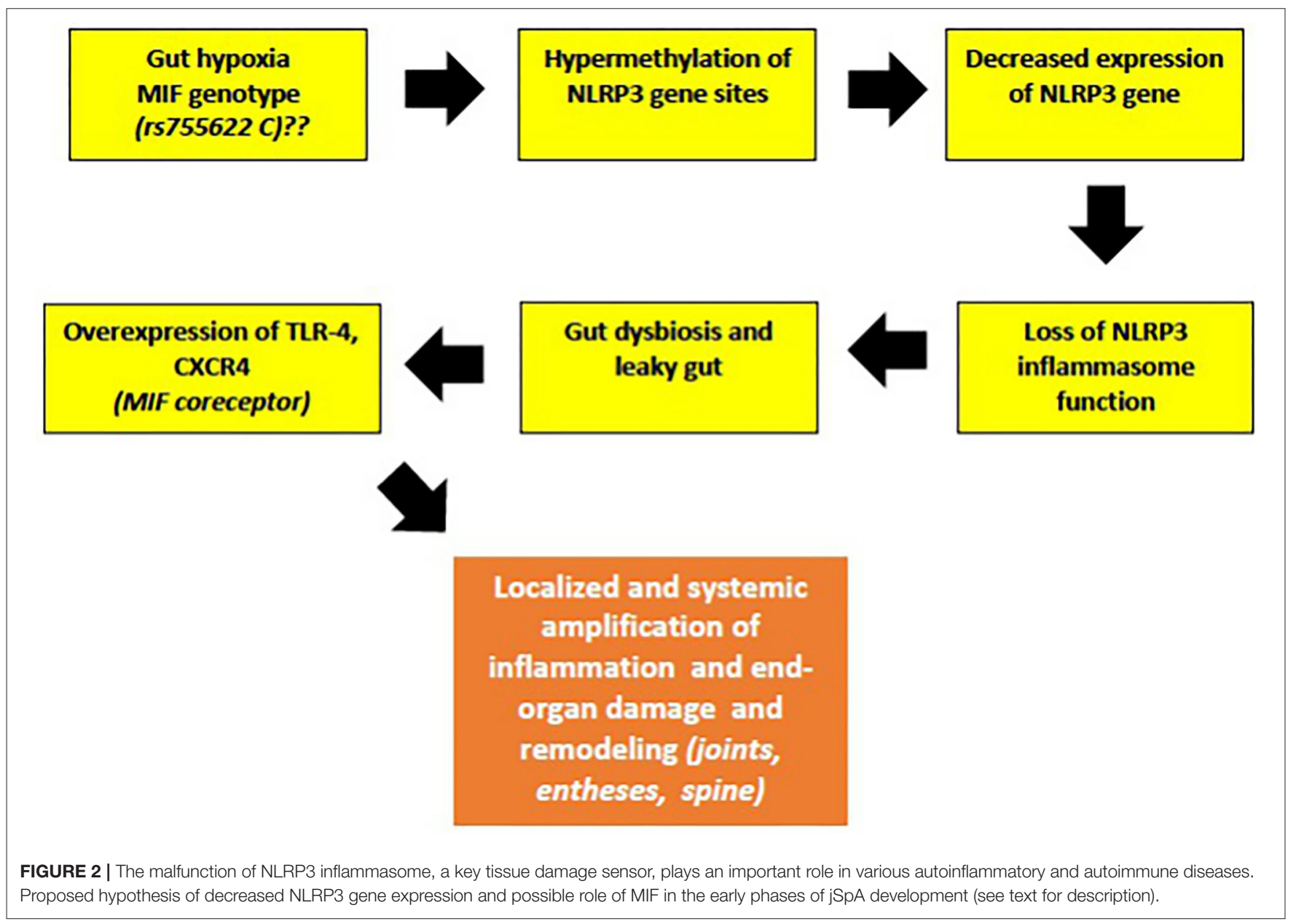


inflammatory response in patients with AS by targeting MIF (132). Similarly to AS, the anti-inflammatory and anti-migratory effects of miR-451 that resulted in suppression of MIF, IL-6, TNF- $\alpha$ or RANTES expression, have been described in vitro in dendritic cells and synovial fibroblasts of RA patients and in vivo in mice with collagen-induced arthritis $(133,134)$.

In the joints themselves, MIF is also involved in synovial angiogenesis and neovascularization enhanced by loss of autophagy/ mitophagy (135). A dysregulation of these mechanisms is a critical mechanisms in the progression of inflammatory arthritis, including SpA (136). Transgenic mice overexpressing MIF exhibit high-turnover osteoporosis, while in different animal models MIF is able to enhance osteoclastogenesis through downmodulation of SDF-1 production in bone tissue and chemoattraction of circulating CXCR4+ osteoclast precursor cells (OCPs) (137-139). Furthermore, MIF (-/-) and CD74(-/-) mice also exhibit a practical absence of osteoclasts at the synovium-bone junction, as well as reduced osteoclast-related gene expression. This indicates that MIF and CD74 accelerate RANKL-induced osteoclastogenesis, suggesting that MIF contributes directly to inflammation and bone erosion in those animals (139). Nevertheless, the variety of bone pathology seen in SpA is unique in medicine and includes increased bone turnover, bone loss, osteitis, osteolysis and erosion, osteoproliferation as well as NBF, either at peripheral (enthesophytes) or axial (syndesmophytes) skeletal ligament, or tendon entheses and osteosclerosis (140). Notably, these effects can be present concurrently in the same patient.

The immunopathogenesis of SpA, with the complex interactions of cellular and main effector cytokine network mediated by MIF, are displayed in Figure 3.

\section{PUTTING IT ALL TOGETHER}

Similar to adults, juvenile spondyloarthritis consists of chronic inflammation, articular bone erosions and pathologic new bone formation. Based on these differences with prototypical autoimmune diseases, such as rheumatoid arthritis or other connective tissue diseases, SpA may be better classified among autoinflammatory diseases (176). Children with clavicular cortical hyperostosis $(\mathrm{CCH})$, a rare manifestation of jSpA, show complex patterns of gene expression related to several inflammatory pathways. These include STAT3 downregulation, B-cell activation, apoptosis, and MAP kinase with upregulated TRPM3/7 $\mathrm{Ca}^{++}$channels, and the most interestingly, genes closely linked to autoinflammatory diseases PTPN12 and MEFV. Interestingly, stimulation of TRPM $3 / 7 \mathrm{Ca}^{++}$channels can provide a second signal for NLRP3 inflammasome activation suggesting that $\mathrm{CCH}$ might be indeed an early autoinflammatory presentation of jSpA [manuscript in preparation, (177)].

A crucial event in the early stages of SpA appears to be the strong association of osteitis with low-grade IBD, confirmed in children with ErA by elevated concentration of fecal calprotectin (fCAL), a surrogate marker of gut inflammation $(178,179)$. Additionally, early studies with colonoscopy have shown that patients with SpA who had sub-clinical inflammation were more likely to have active arthritis on follow up, in particular in the hip, emphasizing therefore the prognostic value of this finding (180, 181). Nonetheless, the cell types that are principally involved in local inflammation in human SpA remain largely unclear (Figure 3). Circulation of immunological cells from the intestines (e.g., entero-synovial circulation) to the entheses, synovium and spine permits the enthesitis and synovitis to become chronic. The separation between the innate and adaptive immune system is largely artificial as neither works in isolation and cross-talks are well reported. The $\mathrm{SpA}$ also requires specific innate and adaptive immunological events targeting the synovium with several processes that run in parallel, such as dysregulated epigenetic control, tissue hypoxia (gut and joint) and neoangiogenesis, all leading to the final stage of tissue damage and remodeling characterized by chronic synovitis and enthesitis, syndesmophyte formation and ankylosis (Figure 4).

However, considering that the frequencies of HLA-B*27 alleles and ERAP1 polymorphisms ("first hit") are ethnicspecific, it is important to understand that jSpA pathogenesis could well be the result of various combinations of these mechanisms in different populations $(182,183)$. It is also important to underline sex differences. Examples include SLE and adult AS where different clinical phenotypes exist in males and females. Therefore, different sexes may require different biomarkers for proper diagnosis of the same disease (184). Nevertheless, two scenarios of disease development are possible: some patients who had reactive arthritis or early undifferentiated form like ErA, can reach remission ("second hit"), but the majority of the patients progresses to active chronic disease ("multiple hits"). The neuroendocrine immune response of the HPA axis and sympathetic nervous system, intended to overcome a transient inflammatory episode, are uncoupled and can therefore lead to immune cell metabolic disease in the context of erroneous energy regulation $(45,66$, 175). Furthermore, failed autophagy and apoptosis of immune cells, in addition to failure of negative immune regulation (e.g., immune suppression) due to decreased GC production (high MIF production), blocked AMP-activated protein kinase (AMPK) pathway, and decreased IL-10 production by TREGs, BREGs, regulatory DCs most likely due to IL-7/HIF-1 production, collectively result in the progression to chronic inflammation and subtype/endotype differentiation $(185,186)$ (Figure 4). Of note is that the activated AMPK, and mammalian target of rapamycin (mTOR), a downstream molecule of activated AMPK, represent key control points of a series of inter-connected inflammatory signaling pathways. These include NF-к $\beta$ and JAK/STAT, crucial drivers of maintaining energy balance, cytokine signaling, cell growth, and apoptosis (187). Interestingly, in the HLA-B27/h $\beta 2$ transgenic rat model where in vivo, prophylactic treatment of rats with rapamycin (m-TOR inhibitor) significantly inhibited the development and severity of inflammation in peripheral joints and spine (arthritis and spondylitis), with histological evidence of reduced bone erosions and new bone formation, all hallmarks of SpA (188). This is relevant in view of the fact that mTOR pathway has been indeed activated in SpA synovitis, and because mTOR blockade by rapamycin or metformin in mouse model 


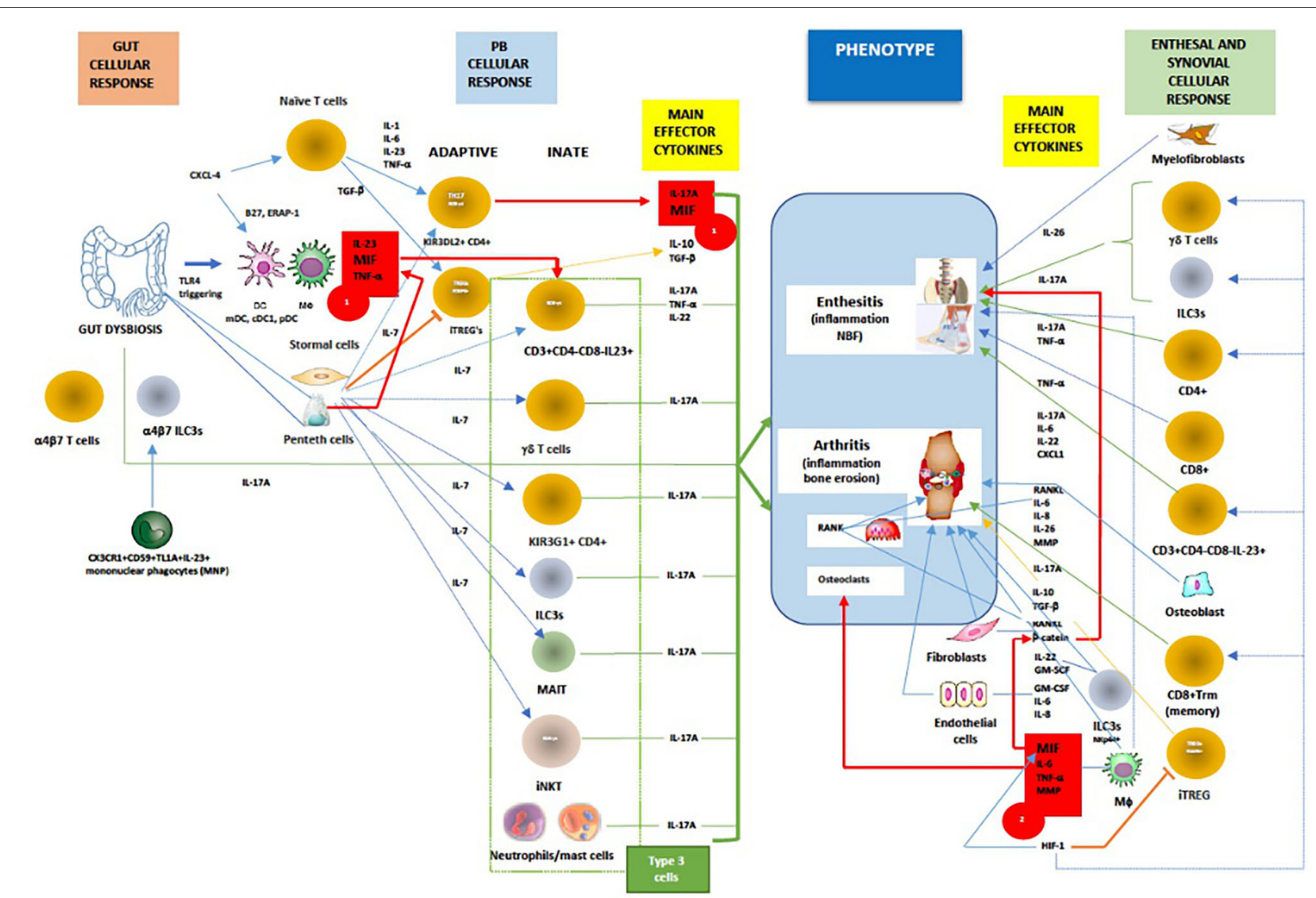

FIGURE 3 | In general, MIF is an proximal mediator of host defense that up-regulates the expression of pattern recognition receptors (eg TLR-4) and perpetuates inflammatory responses by inhibiting activation-induced apoptosis in monocytes and macrophages. As mentioned above in chronic spondyloarthritis the inhibitory effect of glucocorticoids on cytokine mRNA translation may be counter-regulated by MIF. Furthermore, dysbiosis could trigger TLR- 4 ligands to induce ileal production of MIF, especially in CD163+ macrophages, DCs and Paneth cells, which consequently activates CD14+ monocytes to produce TNF- $\alpha / \mathrm{IL}-23$ and primes adaptive and innate (Type 3) immune cells to produce IL-17A (Red box 1). Chemokine CXCL4 (MIF co-receptor) promotes IL-17 production in human CD4+ ${ }^{+}$T cells by acting both directly on CD3/CD28-activated human (naive) CD4+ T cells or indirectly via myeloid antigen presenting cells (mDCs). On the other hand, IL-7 is a cytokine that, better than IL-23, stimulates IL-17 production in both innate and adaptive immunity, and suppress the function of regulatory T cells (Treg). High levels of IL-7 have been confirmed both in the intestinal tissue and in the inflamed synovium of patients with AS. The tissue-resident $\gamma \delta \mathrm{T} \mathrm{cells,} \mathrm{ILC3s,} \mathrm{circulating} \mathrm{and/or} \mathrm{gut-derived} \alpha 4 \beta 7$ $\gamma \delta \mathrm{T}$ cells, $\mathrm{T}_{H} 17$ cells, or mucosal associated invariant T (MAIT) cells all are known to promote IL-17-driven joint/entheseal inflammation. MIF, along with TNF- $\alpha$ and other pro-inflammatory cytokines, also induces synovitis and enthesitis with bone erosions. Joint hypoxia induces hypoxia inducible factor (HIF) expression that augments inflammation-promoting Th17 cell development through recruitment to the IL-17 promoter. In parallel, HIF-1, by binding to Foxp3, restricts regulatory T cell (Treg) development. Through positive feedback loop HIF-1 induces MIF, which in turn causes HIF-1 expression via the MIF receptor (CD74). In contrast to early phases of SpA, axial inflammation is not dependent on IL-23, but rather on IL-17A and most likely MIF. MIF is inducing mineralization of primary osteoblasts in a dose-dependent manner, upregulates genes involved in osteogenesis and triggers stabilization of a known mediators of osteoblastic activity, namely $\beta$-catenin and wingless protein ligand (Wnt). (Red box 2). Beside MIF, upregulated PGE2, IL-1 $\beta$, TNF- $\alpha$, IL-17A, IL-22, IL-26 and IL-23, BMP-2, calcium-sensing receptor CaSR-PLC $\gamma$-signaling and downregulated sclerostin, ankylosis progressive homolog (ANKH) and Dikkopf-1 (DKK-1) protein are important pathways involved in bone remodeling and tissue repair. Finally, activation of both the canonical Wnt/ $\beta$-catenin and noncanonical Wnt/PKC $\delta$ pathways is required for inflammation-induced new bone formation (NBF) in SpA. Taken all together, it still unknow what is/are the most important factors in NBF, even TREGS were recently proposed to paradoxically, via IL-10, promote NBF through suppressing TH17 production [adapted modified from (80, 84, 87, 119, 130-175)]. Red line/box- MIF pathway; green line -IL-17A production; orange line- iTREG suppression and signaling; dotted blue line-IL-7 signaling; blue line-cellular stimulation by other cytokines.

stops osteoclastogenesis. In humans with AS, that blockade also attenuates inflammation, inhibits production of IL-17A and $\mathrm{TNF}-\alpha$, bone remodeling and new periosteal bone formation (189-192). Also, rapamycin in vitro, may reduce inflammation in SpA by promoting autophagy of misfolded HLA-B27 (193).

In undetermined disease stage of $\mathrm{jSpA}$, without well-defined and serological testing, genomic and/or imaging biomarkers become crucial because, despite biologic therapy, fewer than half of children achieve reach long-term and sustainable remission off medication 5 years after diagnosis $(2,194)$. Similarly, treatment of the various bone pathology in SpA remains an unmet clinical need. Although the beneficial effect of anti-TNF- $\alpha$ therapy might not only neutralize the effects of TNF- $\alpha$, but also down-regulate Th17 and Th17-related cytokines associated with up-regulating 


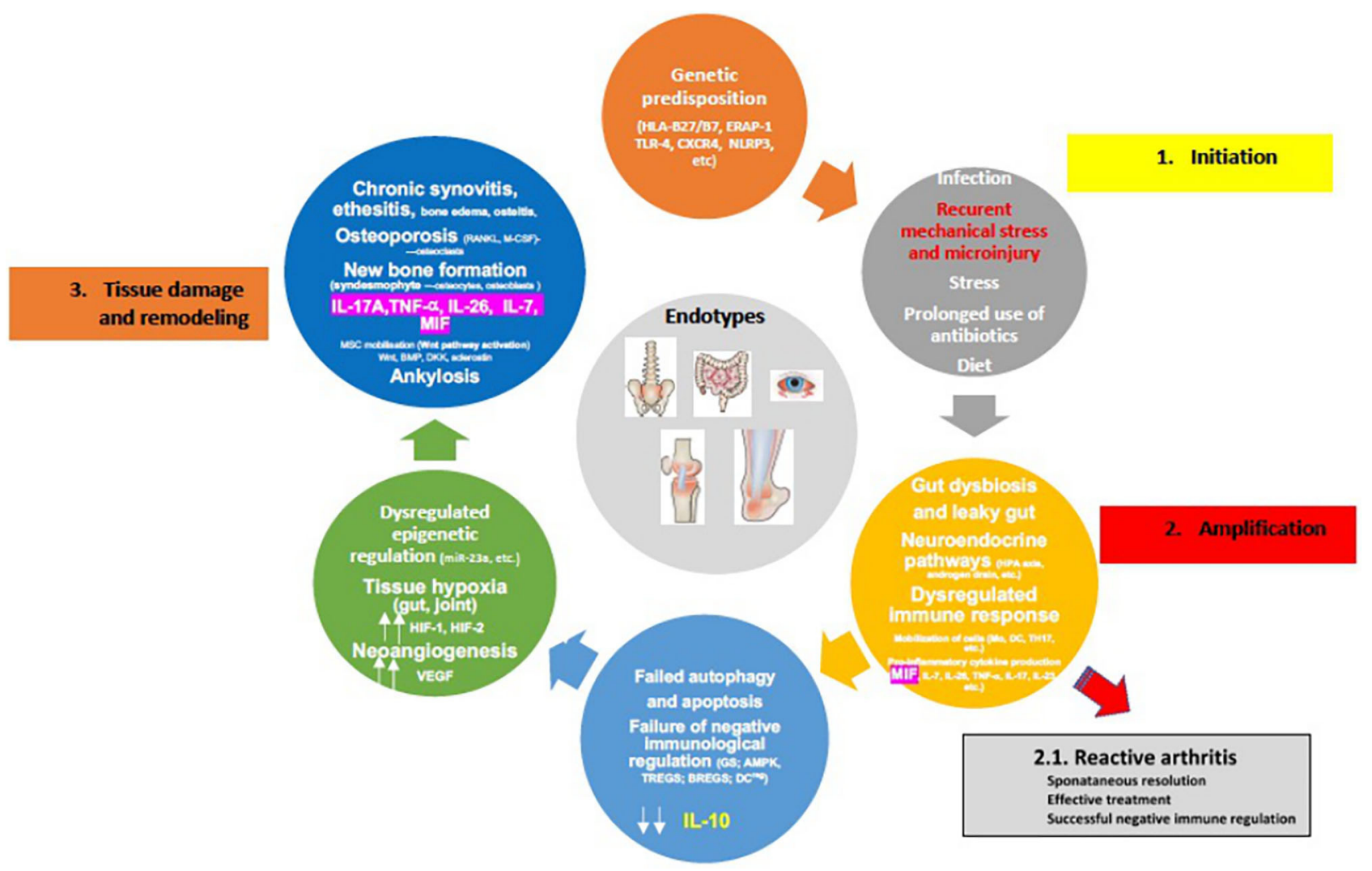

FIGURE 4 | Proposed pathophysiology of spondyloarthritis development (for details please see text). [Adopted modified from (154)].

the TREG/TGF- $\beta$ axis in responders, this can also passively cause new bone formation since TNF- $\alpha$ stimulates the expression of DKK-1. DKK-1 in turn suppresses signaling by Wnt, promoting consequently osteoblast and osteoclast formation as well as differentiation induced by BMP-2 (195).

The definition of disease subtypes on the basis of underlying pathophysiology and the concept of endotypes has emerged more recently. Phenotypes/endotypes are dynamic, clearly overlapping and may evolve into one another, thus making clearcut definitions somehow difficult. Nevertheless, a phenotype/endotype-based classification approach could direct toward the application of personalized/precision medicine in the SpA field. Discoveries from basic science research might, as mentioned above, define multiple complex molecular pathways involved in the pathogenesis of $\mathrm{jSpA}$, which may provide biomarkers for the molecular endotyping of this complex disease. In addition, these molecular pathways might reveal potential therapeutic targets. An endotype might consist of several complex mechanisms that cannot be clearly separated into "pure single molecular mechanism" thus being a "complex" endotype (196). Therefore, new powerful biomarker like fCAL that is able to differentiate various JIA subtypes, would allow us to precisely define various potential endotypes of jSpA. Down that line it was recently demonstrated that in patients with AS, a small RNA molecule, miR-199a-5p was downregulated in T cells and associated with radiographic severity of disease when compared to controls (197). MiRNA-199a-5p expression levels also showed significant negative correlations with the Ankylosing Spondylitis Disease Activity Score (ASDAS) and modified Stoke Ankylosing Spon dylitis Spinal Score (mSASSS) of AS patients. It turns out that, in T cells of AS patients, miR-199a-5p has a novel role in regulating autophagy by modulating the mTOR signaling though direct inhibition of Rheb. Rheb is known to inhibit $\mathrm{T}$ cells autophagy and promotes pro-inflammatory cytokine production by activating mTOR signaling (197). These data suggest that miR-199a-5p participates in the regulation of AS pathogenesis by affecting T cell autophagy and mTOR inhibition (197). In addition, the level of expression of another miR451 was lower in AS PBMCs than in both pSpA and control PBMCs, but MIF expression was significantly increased in AS PBMCs compared to AS patients and with greater radiographic damage. It turns out, that overexpression of miR-451 suppresses the MIF (132). These findings suggest miR-451/MIF may be a novel therapeutic target in the treatment of SpA. Besides that, epigenetics could potentially be used as preventive, diagnostic, and therapeutic biomarkers and should be included in any future jSpA classification and determination of endotypes.

Well established treatment for jSpA still includes NSAIDs, but only sulfasalazine, as one of the conventional DMARDs, was found to be effective in a randomized double blind placebo 
controlled trial in 33 patients with jSpA after 26 weeks treatments (198). While adult with SpAs respond well to treatments that include TNF- $\alpha$ or IL-17-targeting biologics, they are mostly unresponsive to abatacept or MTX treatment $(80,199)$. Secukinumab clinical trial in children with jSpA has recently been completed (ClinicalTrials.gov: NCT03031782) but among other IL17 blocking agents, such as ixekizumab and brodalumab, that were proven to effective for adult axSpA and psoriatic arthritis, only clinical trial of ixekizumab is apparently planned in jSpA (ClinicalTrials.gov: NCT04527380) (200). Also, clinical trials of JAK inhibitors are underway in patients with JIA, including patients with ERA and psoriatic arthritis (ClinicalTrials.gov: NCT02592434, ClinicalTrials.gov: NCT03773978) (200). JAK inhibitors, in particular Tofacitinib, has shown similar efficacy to TNF inhibitors in adult SpA, including axSpA and psoriatic arthritis $(201,202)$.

Finally, to ultimately improve treatment efficacy and longterm outcome of patients with jSpA, consideration should be given for the use of new drugs such as iguratimod (IGU) that target simultaneously MIF, IL-17A and TNF- $\alpha$, or for those that only target IL-7, m-TOR, IL-26 and/or ERAP 1 (203, 204). Blockage of MIF by a monoclonal antibody provides in vivo antirheumatic effects, suggesting MIF as a suitable target for antirheumatic therapy (205). Furthermore, in recent experiments, treatment of RA patients with histone deacetylase inhibitors (HDACi) downregulate MIF, in particular with two distinct orally active molecules MS-275 and SAHA. They have shown in vivo anti-inflammatory activities in preclinical models of rheumatoid arthritis, and both MS-275 and SAHA strongly suppress MIF protein expression by interfering with the MIF transcriptional machinery in RA synovial fibroblasts (206). Givinostat, a pan-class I/II HDACi, is currently being investigated in JIA but no data about its potential use in jSpA is currently available (207). An additional benefit of antiMIF therapy is that it could in addition be steroid-sparing in patients with chronic steroid dependence or refractory rheumatic disease requiring daily steroid therapy. In children and adults, combination of two biologic agents is not well documented. Safety of rituximab in combination with other biologic agents

\section{REFERENCES}

1. Harjacek M, Lamot L, Tambić Bukovac L, Vidović M, Joos R. Challenges in Rheumatology (M. Harjaček editor) Juvenile spondyloarthropathies. InTech, Open Access. (2011) doi: 10.5772/39149

2. Mistry RR, Patro P, Agarwal V, Misra DP. Enthesitis-related arthritis: current perspectives. Open Access Rheumatol. (2019) 11:19-31. doi: 10.2147/OARRR.S163677

3. Maniscalco V, Marrani E, Lamot L, Lionetti P, Simonini G. The conundrum of juvenile spondyloarthritis classification: Many names for a single disease? Lesson learned from an instructive clinical case. Int J Rheum Dis. (2020) 23:1248-51. doi: 10.1111/1756-185X.13922

4. Gmuca S, Weiss PF. Juvenile spondyloarthritis. Curr Opin Rheumatol. (2015) 27:364-72. doi: 10.1097/BOR.0000000000000185

5. Watad A, Cuthbert RJ, Amital H, McGonagle D. Enthesitis: Much More Than Focal Insertion Point Inflammation. Curr Rheumatol Rep. (2018) 20:41. doi: 10.1007/s11926-018-0751-3 (adalimumab, etanercept, infliximab) in adults with RA was reported as an open-label study (208). Rigby et al. showed that no serious adverse events occurred within $24 \mathrm{~h}$ of any rituximab infusion, and that efficacy improved at week 48 compared with that at week 24 (208). However, none of the biologic combination therapy have ever been studied in children, but favorable adverse reaction profiles, with not significant increase in infection rates with mono biologic therapy, might stimulate future researchers to consider combination therapy in children as well. Finally, another interesting approach was performed using bispecific antibody where combining a wellestablished anti-TNF therapeutic domain [single-chain variable fragment $(\mathrm{scFv})$ of adalimumab with a synovial tissue specific targeting domain (scFv-A7) (e.g., scFv-A7 antibody) was located on the human arthritic synovium in vitro and in a synovium xenograft in severe combined immune deficient (SCID) mouse model (209). This study provided the first description of a BsAb capable of direct drug delivery to synovium with potential applications to other existing biologics. In practical terms, due to the improved potency, the use of such BsAb molecules in the clinical care of chronic arthritis like jSpA may offer reduced duration of treatment and consequently reducing the associated healthcare costs.

Finally, future network analysis using multiomics approach to integrate emerging forms of data from multiple platforms, has the potential to further highlights overall imunopathogenesis of the jSpA and offer true biological classification of childhood arthritis as suggested recently $(210,211)$.

\section{AUTHOR CONTRIBUTIONS}

The author confirms being the sole contributor of this work and has approved it for publication.

\section{ACKNOWLEDGMENTS}

The author is grateful to Hassib Narchi for the critical review of the paper, and to Lovro Lamot for his continuous work on the subject.
6. Ramanathan A, Srinivasalu H, Colbert RA. Update on juvenile spondyloarthritis. Rheum Dis Clin North Am. (2013) 39:76788. doi: 10.1016/j.rdc.2013.06.002

7. Brown MA, Laval SH, Brophy S, Calin A. Recurrence risk modelling of the genetic susceptibility to ankylosing spondylitis. Ann Rheum Dis. (2000) 59:883-6. doi: 10.1136/ard.59.11.883

8. Sanz-Bravo A, Alvarez-Navarro C, Martín-Esteban A, Barnea E, Admon A, López de Castro JA. Ranking the Contribution of Ankylosing Spondylitis-associated Endoplasmic Reticulum Aminopeptidase 1 (ERAP1) Polymorphisms to Shaping the HLA-B*27 Peptidome. Mol Cell Proteomics. (2018) 17:1308-23. doi: 10.1074/mcp.RA117.0 00565

9. Hinks A, Martin P, Flynn E, Eyre S, Packham J, Childhood Arthritis Prospective Study-CAPS, et al. Subtype specific genetic associations for juvenile idiopathic arthritis: ERAP1 with the enthesitis related arthritis subtype and IL23R with juvenile psoriatic arthritis. Arthritis Res Ther. (2011) 13:R12. doi: 10.1186/ar3235 
10. Chen L, Ridley A, Hammitzsch A, Al-Mossawi MH, Bunting H, Georgiadis D, et al. Silencing or inhibition of endoplasmic reticulum aminopeptidase 1 (ERAP1) suppresses free heavy chain expression and Th17 responses in ankylosing spondylitis. Ann Rheum Dis. (2016) 75:91623. doi: 10.1136/annrheumdis-2014-206996

11. Barnes MG, Aronow BJ, Luyrink LK, Moroldo MB, Pavlidis $\mathrm{P}$, Passo $\mathrm{MH}$, et al. Gene expression in juvenile arthritis and spondyloarthropathy: pro-angiogenic ELR+ chemokine genes relate to course of arthritis. Rheumatology (Oxford). (2004) 43:973-9. doi: 10.1093/rheumatology/keh224

12. Myles A, Tuteja A, Aggarwal A. Synovial fluid mononuclear cell gene expression profiling suggests dysregulation of innate immune genes in enthesitis-related arthritis patients. Rheumatology (Oxford). (2012) 51:17859. doi: 10.1093/rheumatology/kes151

13. Lamot L, Borovecki F, Tambic Bukovac L, Vidovic M, Perica M, Gotovac $\mathrm{K}$, et al. Aberrant expression of shared master-key genes contributes to the immunopathogenesis in patients with juvenile spondyloarthritis. PLOS ONE. (2014) 9:e115416. doi: 10.1371/journal.pone.0115416

14. Chen YC, Wang PW, Pan TL, Bazylak G, Shen JJ. Proteomic analysis of plasma to reveal the impact of short-term etanercept therapy in pediatric patients with enthesitis-related arthritis: a case report. Comb Chem High Throughput Screen. (2010) 13:469-81. doi: 10.2174/138620710791515987

15. Peffers MJ, Smagul A, Anderson JR. Proteomic analysis of synovial fluid: current and potential uses to improve clinical outcomes. Expert Rev Proteomics. (2019) 16:287-302. doi: 10.1080/14789450.2019.1578214

16. Yang $\mathrm{H}$, Chen $\mathrm{Y}, \mathrm{Xu} \mathrm{W}$, Shao $\mathrm{M}$, Deng J, Xu S, et al. Epigenetics of ankylosing spondylitis: Recent developments. Int J Rheum Dis. (2021) 24:487-93. doi: 10.1111/1756-185X.14080

17. Hammaker D, Firestein GS. Epigenetics of inflammatory arthritis. Curr Opin Rheumatol. (2018) 30:188-96. doi: 10.1097/BOR.0000000000000471

18. Kato M, Yasuda S, Atsumi T. The role of genetics and epigenetics in rheumatic diseases: are they really a target to be aimed at? Rheumatol Int. (2018) 38:1333-8. doi: 10.1007/s00296-018-4026-0

19. Zhang L, Lu Q, Chang C. Epigenetics in Health and Disease. Adv Exp Med Biol. (2020) 1253:3-55. doi: 10.1007/978-981-15-3449-2_1

20. Chavez-Valencia RA, Chiaroni-Clarke RC, Martino DJ, Munro JE, Allen $\mathrm{RC}$, Akikusa JD, et al. The DNA methylation landscape of $\mathrm{CD} 4^{+} \mathrm{T}$ cells in oligoarticular juvenile idiopathic arthritis. J Autoimmun. (2018) 86:2938. doi: 10.1016/j.jaut.2017.09.010

21. Meyer B, Chavez RA, Munro JE, Chiaroni-Clarke RC, Akikusa JD, Allen RC, Craig JM, Ponsonby AL, Saffery R, Ellis JA. DNA methylation at IL32 in juvenile idiopathic arthritis. Sci Rep. (2015) 5:11063. doi: 10.1038/srep11063

22. Charras A, Hedrich CM. The role of epigenetics in paediatric rheumatic disease. Curr Opin Rheumatol. (2019) 31:45063. doi: 10.1097/BOR.0000000000000627

23. Poli G, Fabi C, Bellet MM, Costantini C, Nunziangeli L, Romani L, et al. Epigenetic Mechanisms of Inflammasome Regulation. Int J Mol Sci. (2020) 21:5758. doi: 10.3390/ijms21165758

24. Lamot, L, BlaŽeković A, Jerčić KG, Ivković TC, Vidović M, Lamot M, et al. Epigenetic alterations in juvenile spondyloarthritis patients: a preliminary study of selected genes promoter methylation and silencing. SN Compr Clin Med. (2019) 496-501. doi: 10.1007/s42399-019-00070-9

25. Martini A, Ravelli A, Avcin T, Beresford MW, Burgos-Vargas R, Cuttica R, et al. Pediatric Rheumatology International Trials Organization (PRINTO) Toward new classification criteria for juvenile idiopathic arthritis: first steps, pediatric rheumatology international trials organization international consensus. J Rheumatol. (2019) 46:190-197. doi: 10.3899/jrheum.180168

26. Hao J, Liu Y, Xu J, Wang W, Wen Y, He A,et al. Genome-wide DNA methylation profile analysis identifies differentially methylated loci associated with ankylosis spondylitis. Arthritis Res Ther. (2017) 19:177. doi: 10.1186/s13075-017-1382-1

27. Aslani S, Mahmoudi M, Garshasbi M, Jamshidi AR, Karami J, Nicknam MH. Evaluation of DNMT1 gene expression profile and methylation of its promoter region in patients with ankylosing spondylitis. Clin Rheumatol. (2016) 35:2723-273. doi: 10.1007/s10067-016-3403-x

28. Karami J, Mahmoudi M, Amirzargar A, Gharshasbi M, Jamshidi A, Aslani $\mathrm{S}$, et al. Promoter hypermethylation of BCL11B gene correlates with downregulation of gene transcription in ankylosing spondylitis patients. Genes Immun. (2017) 18:170-175. doi: 10.1038/gene.2017.17

29. Coit P, Kaushik P, Caplan L, Kerr GS, Walsh JA, Dubreuil M, et al. Genomewide DNA methylation analysis in ankylosing spondylitis identifies HLAB*27 dependent and independent DNA methylation changes in whole blood. J Autoimmun. (2019) 102:126-32. doi: 10.1016/j.jaut.2019.04.022

30. Qian BP, Ji ML, Qiu Y, Wang B, Yu Y, Shi W, Luo YF. Identification of Serum miR-146a and miR-155 as Novel Noninvasive Complementary Biomarkers for Ankylosing Spondylitis. Spine (Phila Pa 1976). (2016) 41:735-42. doi: 10.1097/BRS.0000000000001339

31. McCoy CE, Sheedy FJ, Qualls JE, Doyle SL, Quinn SR, Murray PJ, et al. IL-10 inhibits miR-155 induction by toll-like receptors. J Biol Chem. (2010) 285:20492-8. doi: 10.1074/jbc.M110.102111

32. Galluzzi L, Yamazaki T, Kroemer G. Linking cellular stress responses to systemic homeostasis. Nat Rev Mol Cell Biol. (2018) 19:731-45. doi: 10.1038/s41580-018-0068-0

33. de Brouwer SJ, Kraaimaat FW, Sweep FC, Creemers MC, Radstake TR, van Laarhoven AI, et al. Experimental stress in inflammatory rheumatic diseases: a review of psychophysiological stress responses. Arthritis Res Ther. (2010) 12:R89. doi: 10.1186/ar3016

34. Lindström JU, Exarchou S, Lie E, Dehlin M, Forsblad-d'Elia H, Askling J, Jacobsson L. Childhood hospitalisation with infections and later development of ankylosing spondylitis: a national case-control study. Arthritis Res Ther. (2016);18:240. doi: 10.1186/s13075-016-1 141-8

35. Jacques P, Lambrecht S, Verheugen E, Pauwels E, Kollias G, Armaka M, et al. Proof of concept: enthesitis and new bone formation in spondyloarthritis are driven by mechanical strain and stromal cells. Ann Rheum Dis. (2014) 73:437-45. doi: 10.1136/annrheumdis-2013-203643

36. Tapia-Serrano R, Jimenez-Balderas FJ, Murrieta S, Bravo-Gatica C, Guerra R, Mintz G. Testicular function in active ankylosing spondylitis. Therapeutic response to human chorionic gonadotrophin. J Rheumatol. (1991) 18:841-8.

37. Gooren LJ, Giltay EJ, van Schaardenburg D, Dijkmans BA. Gonadal and adrenal sex steroids in ankylosing spondylitis. Rheum Dis Clin North Am. (2000) 26:969-87. doi: 10.1016/S0889-857X(05)70179-4

38. Jeong H, Bae EK, Kim H, Eun YH, Kim IY, Kim H, et al. Estrogen attenuates the spondyloarthritis manifestations of the SKG arthritis model. Arthritis Res Ther. (2017) 19:198. doi: 10.1186/s13075-017-1407-9

39. Tyagi AM, Srivastava K, Mansoori MN, Trivedi R, Chattopadhyay N, Singh D. Estrogen deficiency induces the differentiation of IL-17 secreting Th17 cells: a new candidate in the pathogenesis of osteoporosis. PLoS ONE. (2012) 7:e44552. doi: 10.1371/journal.pone.0044552

40. Aydin T, Karacan I, Demir SE, Sahin Z. Bone loss in males with ankylosing spondylitis: its relation to sex hormone levels. Clin Endocrinol (Oxf). (2005) 63:467-9. doi: 10.1111/j.1365-2265.2005.02369.x

41. Straub RH, Paimela L, Peltomaa R, Schölmerich J, Leirisalo-Repo M. Inadequately low serum levels of steroid hormones in relation to interleukin- 6 and tumor necrosis factor in untreated patients with early rheumatoid arthritis and reactive arthritis. Arthritis Rheum. (2002) 46:65462. doi: 10.1002/art.10177

42. Kebapcilar L, Bilgir O, Alacacioglu A, Yildiz Y, Taylan A, Gunaydin R, et al. Impaired hypothalamo-pituitary-adrenal axis in patients with ankylosing spondylitis. J Endocrinol Invest. (2010) 33:42-47. doi: 10.1007/BF03346548

43. Bilginer Y, Topaloglu R, Alikasifoglu A, Kara N, Besbas N, Ozen S, et al. Low cortisol levels in active juvenile idiopathic arthritis. Clin Rheumatol. (2010) 29:309-14. doi: 10.1007/s10067-009-1326-5

44. Bravo G, Zazueta B, Felix A. Juvenile ankylosingspondylitis. Direct relationship between hyperprolactine-mia and interleukin 6. Abstractx. Arthritis Rheum. (1994) 37:S428.

45. Straub RH, Bijlsma JW, Masi A, Cutolo M. Role of neuroendocrine and neuroimmune mechanisms in chronic inflammatory rheumatic diseases-the 10-year update. Semin Arthritis Rheum. (2013) 43:392404. doi: 10.1016/j.semarthrit.2013.04.008

46. Seifert $\mathrm{O}$, Baerwald C. Interaction of pain and chronic inflammation. $Z$ Rheumatol. (2020) 80:205-13. doi: 10.1007/s00393-020-00951-8

47. DeMorrow S. Role of the Hypothalamic-Pituitary-Adrenal Axis in Health and Disease. Int J Mol Sci. (2018) 19:986. doi: 10.3390/ijms19040986 
48. Sattler J, Tu J, Stoner S, Li J, Buttgereit F, Seibel MJ, Zhou H, Cooper MS. Role of 11 $\beta$-HSD type 1 in abnormal HPA axis activity during immune-mediated arthritis. Endocr Connect. (2018) 7:385-94. doi: 10.1530/EC-17-0361

49. Spies CM, Straub RH, Cutolo M, Buttgereit F. Circadian rhythms in rheumatology-a glucocorticoid perspective. Arthritis Res Ther. (2014) 16:S3. doi: $10.1186 /$ ar4687

50. Gubbels Bupp MR, Jorgensen TN. Androgen-Induced Immunosuppression. Front Immunol. (2018) 9:794. doi: 10.3389/fimmu.2018.00794

51. Oyola MG, Handa RJ. Hypothalamic-pituitary-adrenal and hypothalamicpituitary-gonadal axes: sex differences in regulation of stress responsivity. Stress. (2017) 20:476-94. doi: 10.1080/10253890.2017.1369523

52. Calandra T, Bucala R. Macrophage Migration Inhibitory Factor (MIF): A Glucocorticoid Counter-Regulator within the Immune System. Crit Rev Immunol. (2017) 37:359-70. doi: 10.1615/CritRevImmunol.v37.i2-6.90

53. Ralph JA, Ahmed AU, Santos LL, Clark AR, McMorrow J, Murphy EP, et al. Identification of NURR1 as a mediator of MIF signaling during chronic arthritis: effects on glucocorticoid-induced MKP1. Am J Pathol. (2010) 177:2366-78. doi: 10.2353/ajpath.2010.091204

54. Koopman FA, van Maanen MA, Vervoordeldonk MJ, Tak PP. Balancing the autonomic nervous system to reduce inflammation in rheumatoid arthritis. J Intern Med. (2017) 282:64-75. doi: 10.1111/joim.12626

55. Yang EJ, Beck KM, Koo J. Neuromodulation in Psoriasis and Psoriatic Arthritis. Ann Chron Dise. (2018) 2:1003.

56. Reardon C, Murray K, Lomax AE. Neuroimmune Communication in Health and Disease. Physiol Rev. (2018) 98:2287316. doi: 10.1152/physrev.00035.2017

57. Shouman K, Benarroch EE. Peripheral neuroimmune interactions: selected review and some clinical implications. Clin Auton Res. (2021) 1-13. doi: 10.1007/s10286-021-00787-5

58. Kuis W, Vos van Steenwijk CJ, Sinnema G, Kavelaars A, Prakken B, Helders PJ, et al. The autonomic nervous system and the immune system in juvenile rheumatoid arthritis. Brain Behav Immun. (1996) 10:38798. doi: 10.1006/brbi.1996.0034

59. Heijnen CJ, Rouppe van der Voort C, Wulffraat N, van der Net J, Kuis W, Kavelaars A. Functional alpha 1-adrenergic receptors on leukocytes of patients with polyarticular juvenile rheumatoid arthritis. J Neuroimmunol. (1996) 71:223-6. doi: 10.1016/S0165-5728(96)00125-7

60. Straub RH, Härle P. Sympathetic neurotransmitters in joint inflammation. Rheum Dis Clin North Am. (2005) 31:43-59, viii. doi: 10.1016/j.rdc.2004.09.003

61. Westman M, Engström M, Catrina AI, Lampa J. Cell specific synovial expression of nicotinic alpha 7 acetylcholine receptor in rheumatoid arthritis and psoriatic arthritis. Scand J Immunol. (2009) 70:13640. doi: 10.1111/j.1365-3083.2009.02266.x

62. Zhigang Liu, Bo Han, Peijie Li, Zie Wang \& Qing Fan (2014). Activation of $\alpha 7 n A C h R$ by Nicotine Reduced the Th17 Response in $\mathrm{CD} 4^{+} \mathrm{T}$ Lymphocytes. Immunological Investigations. 43:7, 667-74. doi: 10.3109/08820139.2014.914532

63. Das UN. Can vagus nerve stimulation halt or ameliorate rheumatoid arthritis and lupus? Lipids Health Dis. (2011) 10:19. doi: 10.1186/1476-511X-10-19

64. $\mathrm{Lu} \mathrm{J}, \mathrm{Wu} \mathrm{W}$. Cholinergic modulation of the immune system - A novel therapeutic target for myocardial inflammation. Int Immunopharmacol. (2021) 93:107391. doi: 10.1016/j.intimp.2021.107391

65. Rasmussen S, Brock C, Mohr Drewes A, Jensen MP. SAT0298 Transcutaneous vagus nerve stimulation in patients with psoriatic arthritis or ankylosing spondylitis. Annals of the Rheum Dis. (2018) 77:1013. doi: 10.1136/annrheumdis-2018-eular.4731

66. Torres J, Hu J, Seki A, Eisele C, Nair N, Huang R, et al. Infants born to mothers with IBD present with altered gut microbiome that transfers abnormalities of the adaptive immune system to germ-free mice. Gut. (2020) 69:42-51. doi: 10.1136/gutjnl-2018-317855

67. Yatsunenko T, Rey FE, Manary MJ, Trehan I, Dominguez-Bello MG, Contreras $\mathrm{M}$, et al. Human gut microbiome viewed across age and geography. Nature. (2012) 486:222-7. doi: 10.1038/nature11053

68. Gill $\mathrm{T}$, Asquith $\mathrm{M}$, Rosenbaum JT, Colbert RA. The intestinal microbiome in spondyloarthritis. Curr Opin Rheumatol. (2015) 27:319-25. doi: 10.1097/BOR.0000000000000187
69. Stoll ML. Gut microbes, immunity, and spondyloarthritis. Clin Immunol. (2015) 159:134-42. doi: 10.1016/j.clim.2015.05.001

70. Gracey E, Vereecke L, McGovern D, Fröhling M, Schett G, Danese S, et al. Revisiting the gut-joint axis: links between gut inflammation and spondyloarthritis. Nat Rev Rheumatol. (2020) 16:415-433. doi: 10.1038/s41584-020-0454-9

71. Arvonen M, Vänni P, Sarangi AN, V Tejesvi M, Vähäsalo P, Aggarwal A, Stoll ML. Microbial orchestra in juvenile idiopathic arthritis: Sounds of disarray? Immunol Rev. (2020) 294:9-26. doi: 10.1111/imr.12826

72. De Filippo C, Di Paola M, Giani T, Tirelli F, Cimaz R. Gut microbiota in children and altered profiles in juvenile idiopathic arthritis. J Autoimmun. (2019) 98:1-12. doi: 10.1016/j.jaut.2019.01.001

73. Ricciuto A, Sherman PM, Laxer RM. Gut microbiota in chronic inflammatory disorders: A focus on pediatric inflammatory bowel diseases and juvenile idiopathic arthritis. Clin Immunol. (2020) 215:108415. doi: 10.1016/j.clim.2020.108415

74. Xin L, He F, Li S, Zhou ZX, Ma XL. Intestinal microbiota and juvenile idiopathic arthritis: current understanding and future prospective. World $J$ Pediatr. (2021) 17:40-51. doi: 10.1007/s12519-020-00371-3

75. Di Paola M, Cavalieri D, Albanese D, Sordo M, Pindo M, Donati C, et al. Alteration of Fecal Microbiota Profiles in Juvenile Idiopathic Arthritis. Associations with HLA-B27 Allele and Disease Status. Front Microbiol. (2016) 7:1703. doi: $10.3389 /$ fmicb.2016.01703

76. Fragoulis GE, Liava C, Daoussis D, Akriviadis E, Garyfallos A, Dimitroulas T. Inflammatory bowel diseases and spondyloarthropathies: From pathogenesis to treatment. World J Gastroenterol. (2019) 25:2162-76. doi: 10.3748/wjg.v25.i18.2162

77. Gill T, Asquith M, Brooks SR, Rosenbaum JT, Colbert RA. Effects of HLA-B27 on Gut Microbiota in Experimental Spondyloarthritis Implicate an Ecological Model of Dysbiosis. Arthritis Rheumatol. (2018) 70:55565. doi: 10.1002/art.40405

78. Bjerrum JT, Wang Y, Hao F, Coskun M, Ludwig C, Günther U, et al. Metabonomics of human fecal extracts characterize ulcerative colitis, Crohn's disease and healthy individuals. Metabolomics. (2015) 11:12233. doi: 10.1007/s11306-014-0677-3

79. Stoll ML, Kumar R, Lefkowitz EJ, Cron RQ, Morrow CD, Barnes S. Fecal metabolomics in pediatric spondyloarthritis implicate decreased metabolic diversity and altered tryptophan metabolism as pathogenic factors. Genes Immun. (2016) 17:400-5. doi: 10.1038/gene.2016.38

80. Watad A, Bridgewood C, Russell T, Marzo-Ortega H, Cuthbert R, McGonagle D. The Early Phases of Ankylosing Spondylitis: Emerging Insights From Clinical and Basic Science. Front Immunol. (2018) 9:2668. doi: 10.3389/fimmu.2018.02668

81. Vidovic M, Perica M, Lamot L, Zaninovic M, Bukova LT, Harjacek M. PReSFINAL-2074: The role of the probiotic VSL-3 as adjuvant therapy in patients with undifferentiated spondyloarthritis (ERA). Pediatr Rheumatol. (2013) 11: P86. doi: 10.1186/1546-0096-11-S2-P86

82. Shukla A, Gaur P, Aggarwal A. Effect of probiotics on clinical and immune parameters in enthesitis-related arthritis category of juvenile idiopathic arthritis. Clin Exp Immunol. (2016) 185:301-8. doi: 10.1111/cei.12818

83. Li H, Tsokos GC. IL-23/IL-17 Axis in inflammatory rheumatic diseases. Clin Rev Allergy Immunol. (2021) 60:31-45. doi: 10.1007/s12016-020-08823-4

84. Tsukazaki H, Kaito T. The role of the IL-23/IL-17 pathway in the pathogenesis of spondyloarthritis. Int J Mol Sci. (2020) 21:1-19. doi: 10.3390/ijms21176401

85. Maggi L, Mazzoni A, Cimaz R, Liotta F, Annunziato F, Cosmi L. Th17 and Th1 lymphocytes in oligoarticular juvenile idiopathic arthritis. Front Immunol. (2019) 10:450. doi: 10.3389/fimmu.2019.00450

86. Mahendra A, Misra R, Aggarwal A. Th1 and Th17 predominance in the enthesitis-related arthritis form of juvenile idiopathic arthritis. J Rheumatol. (2009) 36:1730-6. doi: 10.3899/jrheum.081179

87. Gonçalves RSG, Duarte ALBP. IL-7 is a Key Driver Cytokine in Spondyloarthritis? J Immunol Res. (2019) 2019:7453236. doi: 10.1155/2019/7453236

88. Menegatti S, Bianchi E, Rogge L. Anti-TNF therapy in spondyloarthritis and related diseases, impact on the immune system and prediction of treatment responses. Front Immunol. (2019) 10:382. doi: 10.3389/fimmu.2019.00382 
89. Marino A, De Souza M, Giani T, Cimaz R. Pharmacotherapy for juvenile spondyloarthritis: an overview of the available therapies. Expert Opin Pharmacother. (2020) 21:2161-8 doi: 10.1080/14656566.2020.1796970

90. Petrovsky N, Socha L, Silva D, Grossman AB, Metz C, Bucala R. Macrophage migration inhibitory factor exhibits a pronounced circadian rhythm relevant to its role as a glucocorticoid counter-regulator. Immunol Cel Biol. (2003) 81:137-143. doi: 10.1046/j.0818-9641.2002.01148.x

91. Farr L, Ghosh S, Moonah S. Role of MIF Cytokine/CD74 Receptor Pathway in Protecting Against Injury and Promoting Repair. Front Immunol. (2020) 11:1273. doi: 10.3389/fimmu.2020.01273

92. Harris J, VanPatten S, Deen NS, Al-Abed Y, Morand EF. Rediscovering MIF: new tricks for an old cytokine. Trends Immunol. (2019) 40:44762. doi: 10.1016/j.it.2019.03.002

93. Ives A, Le Roy D, Théroude C, Bernhagen J, Roger $\mathrm{T}$, Calandra $\mathrm{T}$. Macrophage migration inhibitory factor promotes the migration of dendritic cells through CD74 and the activation of the Src/PI3K/myosin II pathway. FASEB J. (2021) 35:e21418. doi: 10.1096/fj.202001605R

94. Xia W, Hou M. Macrophage migration inhibitory factor induces autophagy to resist hypoxia/serum deprivation-induced apoptosis via the AMPactivated protein kinase/mammalian target of rapamycin signaling pathway. Mol Med Rep. (2016) 13:2619-26. doi: 10.3892/mmr.2016.4847

95. Schindler L, Zwissler L, Krammer C, Hendgen-Cotta U, Rassaf T, Hampton $M B$, et al. Macrophage migration inhibitory factor inhibits neutrophil apoptosis by inducing cytokine release from mononuclear cells. J Leukoc Biol. (2021) 1-13. doi: 10.1002/JLB.3A0420-242RRR. [Epub ahead of print].

96. Chuang YC, Su WH, Lei HY, Lin YS, Liu HS, Chang CP, et al. Macrophage migration inhibitory factor induces autophagy via reactive oxygen species generation. PLoS ONE. (2012) 7:e37613. doi: 10.1371/journal.pone.0037613

97. Du X, Li R, Song S, Ma L, Xue H. The Role of MIF-173G/C Gene Polymorphism in the Susceptibility of Autoimmune Diseases. Mediators Inflamm. (2020) 2020:7825072. doi: 10.1155/2020/7825072

98. Wu J, Chen F, Zhang X, Li Y, Ma H, Zhou Y, et al. Association of MIF promoter polymorphisms with psoriasis in a Han population in northeastern China. J Dermatol Sci. (2009) 53:212-5. doi: 10.1016/j.jdermsci.200 8.11 .002

99. Zhang H, Ma L, Dong LQ, Shu C, Xu JL. Association of the macrophage migration inhibitory factor gene-173G/C polymorphism with inflammatory bowel disease: a meta-analysis of 4296 subjects. Gene. (2013) 526:22831. doi: 10.1016/j.gene.2013.05.012

100. De Benedetti F, Meazza C, Vivarelli M, Rossi F, Pistorio A, Lamb R, et al. Functional and prognostic relevance of the-173 polymorphism of the macrophage migration inhibitory factor gene in systemic-onset juvenile idiopathic arthritis. Arthritis Rheum. (2003) 48:1398-407. doi: 10.1002/art.10882

101. Lue H, Dewor M, Leng L, Bucala R, Bernhagen J. Activation of the JNK signalling pathway by macrophage migration inhibitory factor (MIF) and dependence on CXCR4 and CD74. Cell Signal. (2011) 23:13544. doi: 10.1016/j.cellsig.2010.08.013

102. Mitchell RA, Liao H, Chesney J, Fingerle-Rowson G, Baugh J, David J, et al. Macrophage migration inhibitory factor (MIF) sustains macrophage proinflammatory function by inhibiting p53: regulatory role in the innate immune response. Proc Natl Acad Sci USA. (2002) 99:34550. doi: 10.1073/pnas.012511599

103. Farr L, Ghosh S, Jiang N, Watanabe K, Parlak M, Bucala R, et al. CD74 Signaling Links Inflammation to Intestinal Epithelial Cell Regeneration and Promotes Mucosal Healing. Cell Mol Gastroenterol Hepatol. (2020) 10:10112. doi: $10.1016 /$ j.jcmgh.2020.01.009

104. Sogkas G, Klose K, Baerlecken N, Schweikhard E, Matthias T, Kniesch K, et al. CD74 is a T cell antigen in spondyloarthritis. Clin Exp Rheumatol. (2020) 38:195-202.

105. West PW, Parker LC, Ward JR, Sabroe I. Differential and cell-type specific regulation of responses to Toll-like receptor agonists by ISO-1. Immunology. (2008) 125:101-10. doi: 10.1111/j.1365-2567.2008.02825.x

106. Roger T, Froidevaux C, Martin C, Calandra T. Macrophage migration inhibitory factor (MIF) regulates host responses to endotoxin through modulation of Toll-like receptor 4 (TLR4). J Endotoxin Res. (2003) 9:11923. doi: $10.1179 / 096805103125001513$
107. Perica M, Vidović M, Lamot L, Bukovac LT, Kapitanović S, Perić M, et al. Single nucleotide polymorphism of toll-like receptor 4 (TLR4) is associated with juvenile spondyloarthritis in Croatian population. Clin Rheumatol. (2015) 34:2079-86 doi: 10.1007/s10067-015-2952-8

108. Myles A, Aggarwal A. Lack of association of single nucleotide polymorphisms in toll-like receptors 2 and 4 with enthesitis-related arthritis category of juvenile idiopathic arthritis in Indian population. Rheumatol Int. (2013) 33:417-21. doi: 10.1007/s00296-012-2396-2

109. Kleemann R, Hausser A, Geiger G, Mischke R, Burger-Kentischer A, Flieger $\mathrm{O}$, et al. Intracellular action of the cytokine MIF to modulate AP-1 activity and the cell cycle through Jab1. Nature. (2000) 408:2116. doi: 10.1038/35041591

110. Baugh JA, Donnelly SC. Macrophage migration inhibitory factor: a neuroendocrine modulator of chronic inflammation. J Endocrinol. (2003) 179:15-23. doi: 10.1677/joe.0.1790015

111. Lang T, Lee JPW, Elgass K, Pinar AA, Tate MD, Aitken EH, et al. Macrophage migration inhibitory factor is required for NLRP 3 inflammasome activation. Nat Commun. (2018) 9:2223. doi: 10.1038/s41467-018-04581-2

112. Son CN, Bang SY, Kim JH, Choi CB, Kim TH, Jun JB. Caspase1 level in synovial fluid is high in patients with spondyloarthropathy but not in patients with gout. J Korean Med Sci. (2013) 28:128992. doi: $10.3346 / \mathrm{jkms} .2013 .28 .9 .1289$

113. Glover LE, Colgan SP. Hypoxia and metabolic factors that influence inflammatory bowel disease pathogenesis. Gastroenterology. (2011) 140:1748-55. doi: 10.1053/j.gastro.2011.01.056

114. Singhal R, Shah YM. Oxygen battle in the gut: Hypoxia and hypoxiainducible factors in metabolic and inflammatory responses in the intestine. $J$ Biol Chem. (2020) 295:10493-505. doi: 10.1074/jbc.REV120.011188

115. Lee JS, Wang RX, Alexeev EE, Colgan SP. Intestinal Inflammation as a Dysbiosis of Energy Procurement: New Insights into an Old Topic. Gut Microbes. (2021) 13:1-20. doi: 10.1080/19490976.2021.1880241

116. Kim YI, Yi EJ, Kim YD, Lee AR, Chung J, Ha HC, et al. Local Stabilization of hypoxia-inducible factor-1 $\alpha$ controls intestinal inflammation via enhanced gut barrier function and immune regulation. Front Immunol. (2021) 11:609689. doi: 10.3389/fimmu.2020.609689

117. Sun L, Li T, Tang H, Yu K, Ma Y, Yu M, et al. Intestinal epithelial cellsderived hypoxia-inducible factor- $1 \alpha$ is essential for the homeostasis of intestinal intraepithelial lymphocytes. Front Immunol. (2019) 10:806. doi: 10.3389/fimmu.2019.00806

118. Shah YM, Ito S, Morimura K, Chen C, Yim SH, Haase VH, et al. Hypoxiainducible factor augments experimental colitis through an MIF-dependent inflammatory signaling cascade. Gastroenterology. (2008) 134:2036-48 (2048) e1-3. doi: 10.1053/j.gastro.2008.03.009

119. Gaber T, Schellmann S, Erekul KB, Fangradt M, Tykwinska K, Hahne M, et al. Macrophage migration inhibitory factor counterregulates dexamethasonemediated suppression of hypoxia-inducible factor-1 alpha function and differentially influences human $\mathrm{CD} 4+\mathrm{T}$ cell proliferation under hypoxia. $J$ Immunol. (2011) 186:764-74. doi: 10.4049/jimmunol.0903421

120. Winner M, Koong AC, Rendon BE, Zundel W, Mitchell RA. Amplification of tumor hypoxic responses by macrophage migration inhibitory factordependent hypoxia-inducible factor stabilization. Cancer Res. (2007) 67:18693. doi: 10.1158/0008-5472.CAN-06-3292

121. Kim HR, Park MK, Cho ML, Yoon CH, Lee SH, Park SH, et al. Macrophage migration inhibitory factor upregulates angiogenic factors and correlates with clinical measures in rheumatoid arthritis. J Rheumatol. (2007) 34:92736.

122. Kim SY, Choi YJ, Joung SM, Lee BH, Jung YS, Lee JY. Hypoxic stress up-regulates the expression of Toll-like receptor 4 in macrophages via hypoxia-inducible factor. Immunology. (2010) 129:516-24. doi: 10.1111/j.1365-2567.2009.03203.x

123. Hua S, Dias TH. Hypoxia-Inducible Factor (HIF) as a target for novel therapies in rheumatoid arthritis. Front Pharmacol. (2016) 7:184. doi: 10.3389/fphar.2016.00184

124. Martín R, Bermúdez-Humarán LG, Langella P. Searching for the bacterial effector: the example of the multi-skilled commensal bacterium Faecalibacterium prausnitzii. Front Microbiol. (2018) 9:346. doi: $10.3389 /$ fmicb. 2018.00346 
125. Tourkochristou E, Aggeletopoulou I, Konstantakis C, Triantos C. Role of NLRP3 inflammasome in inflammatory bowel diseases. World J Gastroenterol. (2019) 25:4796-804. doi: 10.3748/wjg.v25.i33.4796

126. Yao X, Zhang C, Xing Y, Xue G, Zhang Q, Pan F, et al. Remodelling of the gut microbiota by hyperactive NLRP3 induces regulatory $\mathrm{T}$ cells to maintain homeostasis. Nat Commun. (2017) 8:1896. doi: 10.1038/s41467-017-01917-2

127. Zhen Y, Zhang H. NLRP3 inflammasome and inflammatory bowel disease. Front Immunol. (2019) 10:276. doi: 10.3389/fimmu.2019.00276

128. Sakurai N, Shibata T, Nakamura M, Takano H, Hayashi T, Ota M, et al. Influence of MIF polymorphisms on $\mathrm{CpG}$ island hyper-methylation of CDKN2A in the patients with ulcerative colitis. BMC Med Genet. (2020) 21:201. doi: 10.1186/s12881-020-01140-9

129. Gürel Ç, Inanir A, Nursal AF, Tekcan A, Rüstemoglu A, Yigit S. Evaluation of MIF-173 G/C polymorphism in turkish patients with ankylosing spondylitis. Balkan Med J. (2016) 33:614-19. doi: 10.5152/balkanmedj.2016.141103

130. Kozaci LD, Sari I, Alacacioglu A, Akar S, Akkoc N. Evaluation of inflammation and oxidative stress in ankylosing spondylitis: a role for macrophage migration inhibitory factor. Mod Rheumatol. (2010) 20:349. doi: 10.3109/s10165-009-0230-9

131. Ranganathan V, Ciccia F, Zeng F, Sari I, Guggino G, Muralitharan J, et al. Macrophage migration inhibitory factor induces inflammation and predicts spinal progression in ankylosing spondylitis. Arthritis Rheumatol. (2017) 69:1796-806. doi: 10.1002/art.40175

132. Park MC, Kwon OC, Lee SW, Song JJ, Park YB. MiR-451 suppresses inflammatory responses in ankylosing spondylitis by targeting macrophage migration inhibitory factor. Clin Exp Rheumatol. (2020) 38:275-81.

133. Wang ZC, Lu H, Zhou Q, Yu SM, Mao YL, Zhang HL, et al. MiR-451 inhibits synovial fibroblasts proliferation and inflammatory cytokines secretion in rheumatoid arthritis through mediating p38MAPK signaling pathway. Int J Clin Exp Pathol. (2015) 8:14562-14567.

134. Murata K, Yoshitomi H, Furu M, Ishikawa M, Shibuya H, Ito H, et al. MicroRNA-451 down-regulates neutrophil chemotaxis via p38 MAPK. Arthritis Rheumatol. (2014) 66:549-559. doi: 10.1002/art.38269

135. Lee JP, Foote A, Fan H, Peral de Castro C, Lang T, Jones SA, et al. Loss of autophagy enhances MIF/macrophage migration inhibitory factor release by macrophages. Autophagy. (2016) 12:907-16. doi: 10.1080/15548627.2016.1164358

136. Ciccia F, Haroon N. Autophagy in the pathogenesis of ankylosing spondylitis. Clin Rheumatol. (2016) 35:1433-6. doi: 10.1007/s10067-016-3262-5

137. Onodera S, Sasaki S, Ohshima S, Amizuka N, Li M, Udagawa N, et al. Transgenic mice overexpressing macrophage migration inhibitory factor (MIF) exhibit high-turnover osteoporosis. J Bone Miner Res. (2006) 21:87685. doi: 10.1359/jbmr.060310

138. Movila A, Ishii T, Albassam A, Wisitrasameewong W, Howait M, Yamaguchi T, et al. Macrophage Migration Inhibitory Factor (MIF) supports homing of osteoclast precursors to peripheral osteolytic lesions. J Bone Miner Res. (2016) 31:1688-700. doi: 10.1002/jbmr.2854

139. Gu R, Santos LL, Ngo D, Fan H, Singh PP, Fingerle-Rowson G, Bucala $\mathrm{R}, \mathrm{Xu}$ J, Quinn JM, Morand EF. Macrophage migration inhibitory factor is essential for osteoclastogenic mechanisms in vitro and in vivo mouse model of arthritis. Cytokine. (2015) 72:135-45. doi: 10.1016/j.cyto.2014. 11.015

140. Clunie G, Horwood N. Loss and gain of bone in spondyloarthritis: what drives these opposing clinical features? Ther Adv Musculoskelet Dis. (2020) 12:1759720X20969260. doi: 10.1177/1759720X20969260

141. Li X, Wang J, Zhan Z, Li S, Zheng Z, Wang T, et al. Inflammation intensitydependent expression of osteoinductive wnt proteins is critical for ectopic new bone formation in ankylosing spondylitis. Arthritis Rheumatol. (2018) 70:1056-70. doi: 10.1002/art.40468

142. Li X, Chen S, Hu Z, Chen D, Wang J, Li Z, et al. Aberrant upregulation of CaSR promotes pathological new bone formation in ankylosing spondylitis. EMBO Mol Med. (2020) 12:e12109. doi: 10.15252/emmm.202012109

143. Stoll ML. Interactions of the innate and adaptive arms of the immune system in the pathogenesis of spondyloarthritis. Clin Exp Rheumatol. (2011) 29:322-30. PMCID: PMC3266164

144. Reinhardt A, Prinz I. Whodunit? The contribution of interleukin (IL)-17/IL-22-producing $\gamma \delta \mathrm{T}$ cells, $\alpha \beta \mathrm{T}$ cells, and innate lymphoid cells to the pathogenesis of spondyloarthritis. Front Immunol. (2018) 9:885. doi: 10.3389/fimmu.2018.00885

145. Mauro D, Macaluso F, Fasano S, Alessandro R, Ciccia F. ILC3 in axial spondyloarthritis: the gut angle. Curr Rheumatol Rep. (2019) 21:37. doi: 10.1007/s11926-019-0834-9

146. Chen S, Paveley R, Kraal L, Sritharan L, Stevens E, Dedi N, et al. Selective targeting of PI3K $\delta$ suppresses human IL-17-producing T cells and innate-like lymphocytes and may be therapeutic for IL-17-mediated diseases. Journal of Autoimmunity. (2020) 111:1-12. doi: 10.1016/j.jaut.2020.102435

147. Watad A, Rowe H, Russell T, Zhou Q, Anderson LK, Khan A, et al. Normal human enthesis harbors conventional CD4+and CD8+ T cells with regulatory features and inducible IL-17A and TNF expression. Ann Rheum Dis. (2020) 79:1044-54. doi: 10.1136/annrheumdis-2020-217309

148. Qaiyum Z, Gracey E, Yao Y, Inman RD. Integrin and transcriptomic profiles identify a distinctive synovial CD8+ T cell subpopulation in spondyloarthritis. Ann Rheum Dis. (2019) 78:1566. doi: 10.1136/annrheumdis-2019-215349

149. Adam Berlinberg A, Kuhn KA. Barrier lymphocytes in spondyloarthritis. Curr Opin Rheumatol. (2020) 32:34348. doi: 10.1097/BOR.0000000000000716

150. Gaston JSH, Jadon DR. Th17 cell responses in spondyloarthritis. Best Pract Res Clin Rheumatol. (2017) 31:777-96. doi: 10.1016/j.berh.2018.07.010

151. Toussirot E, Saas P. MAIT cells: potent major cellular players in the IL-17 pathway of spondyloarthritis? RMD Open. (2018) 4: e000821. doi: 10.1136/rmdopen-2018-000821

152. Venken K, Jacques P, Mortier C, Labadia ME, Decruy T, Coudenys J, et al. ROR $\gamma$ t inhibition selectively targets IL-17 producing iNKT and $\gamma \delta$-T cells enriched in Spondyloarthritis patients. Nat Commun. (2019) 10:9. doi: 10.1038/s41467-018-07911-6

153. Sherlock JP, Joyce-Shaikh B, Turner SP, Chao C-C, Sathe M, Grein J, et al. IL23 induces spondyloarthropathy by acting on ROR- $\gamma \mathrm{t}+\mathrm{CD} 3+\mathrm{CD} 4-\mathrm{CD} 8-$ entheseal resident T cells. (2012) Nat med. 18:1069-77. doi: 10.1038/nm.2817

154. McGonagle DG, McInnes IB, Kirkham BW, Sherlock J, Moots R. The role of IL-17A in axial spondyloarthritis and psoriatic arthritis: Recent advances and controversies. Ann Rheum Dis. (2019) 215356:112. doi: 10.1136/annrheumdis-2019-215356corr1

155. Ciccia F, Guggino G, Zeng M, Thomas R, Ranganathan V, Rahman A, et al. Proinflammatory CX3CR1+CD59+tumor necrosis factor-like molecule $1 \mathrm{~A}+$ interleukin-23+ monocytes are expanded in patients with ankylosing spondylitis and modulate innate lymphoid cell 3 immune functions. Arthritis Rheum. (2018) 12:2003-13. doi: 10.1002/art.40582

156. Furst DE, James S, Louie JS. Targeting inflammatory pathways in axial spondyloarthritis. Arthritis Res Ther. (2019) 21:115. doi: 10.1186/s13075-019-1885-z

157. Heftdal LD, Andersen T, Jæhger D, Woetmann A, Østgård R, Kenngott EE, et al. Synovial cell production of IL-26 induces bone mineralization in spondyloarthritis. J Mol Med. (2017) 95: 779-87. doi: 10.1007/s00109-017-1528-2

158. Corrado A, Maruotti N, Cantatore FP. Osteoblast role in rheumatic diseases. Int J Mol Sci. (2017) 18:1272-84. doi: 10.3390/ijms18061272

159. Pandiyan P, Lenardo MJ. The control of CD4+CD25+Foxp3+ regulatory T cell survival. Biology Direct. (2008) 3:6 doi: 10.1186/1745-6150-3-6

160. Wright $\mathrm{P}$, Lotta Utriainen L, Milling S. Dendritic and regulatory $\mathrm{T}$ cells in spondyloarthritis. Curr Opin Rheumatol (2013) 25:440447. doi: 10.1097/BOR.0b013e32836202dc

161. Baeten D, Demetter P, Cuvelier CA, Kruithof E, Van Damme N, De Vos M, et al. Macrophages expressing the scavenger receptor CD163: a link between immune alterations of the gut and synovial inflammation in spondyloarthropathy. J Pathol. (2002) 196:343-50. doi: 10.1002/pat h. 1044

162. Wright PB, McEntegart A, McCarey D, McInnes IB, Siebert S, Milling SW. Ankylosing spondylitis patients display altered dendritic cell and $\mathrm{T}$ cell populations that implicate pathogenic roles for the IL-23 cytokine axis and intestinal inflammation. Rheumatology (Oxford). (2016) 55:120-32. doi: 10.1093/rheumatology/k ev245

163. Liu C-H, Chou C-T, Chen C-H, Chen C-H, Shii-Yi Yang S-Y et al. Aberrant distribution and function of plasmacytoid dendritic cells in patients 
with ankylosing spondylitis are associated with unfolded protein response. Kaohsiung J Med Sci. (2020) 36:441-449. doi: 10.1002/kjm2.12184

164. Agarwal S, Misra R, Aggarwal A. Interleukin 17 levels are increased in juvenile idiopathic arthritis synovial fluid and induce synovial fibroblasts to produce proinflammatory cytokines and matrix metalloproteinases. $J$ Rheumatol. (2008) 35:515-9.

165. Gaur P, Misra R, Aggarwal A. Natural killer cell and gamma delta $\mathrm{T}$ cell alterations in enthesitis related arthritis category of juvenile idiopathic arthritis. Clin Immunol. (2015) 161:163-9. doi: 10.1016/j.clim.201 5.07 .012

166. Jankauskas SS, Wong DWL, Bucala R, Djudjaj S, Boor P. Evolving complexity of MIF signaling. Cell Signal. (2019) 57:76-88. doi: 10.1016/j.cellsig.2019.01.006

167. Ciccia F, Guggino G, Rizzo A, Saieva L, Peralta S, Giardina A, et al. Type 3 innate lymphoid cells producing IL-17 and IL-22 are expanded in the gut, in the peripheral blood, synovial fluid and bone marrow of patients with ankylosing spondylitis. Ann Rheum Dis. (2015) 74:173947. doi: 10.1136/annrheumdis-2014-206323

168. Rihl M, Kellner H, Kellner W, Barthel C, Yu DTY, Tak PP, et al. Identification of interleukin-7 as a candidate disease mediator in spondylarthritis. Arthritis \& Rheumatism. (2008) 58:3430-35. doi: 10.1002/ar t.23998

169. Belarif L, Danger R, Kermarrec L, Nerrière-Daguin V, Pengam S, Durand $\mathrm{T}$, et al. IL-7 receptor influences anti-TNF responsiveness and T cell gut homing in inflammatory bowel disease. J Clin Invest. (2019) 12:191025. doi: 10.1172/JCI121668

170. Ridley A, Hatano H, Wong-Baeza I, Shaw J, Matthews KK, AlMossawi $\mathrm{H}$, et al. Activation-induced killer cell immunoglobulin-like receptor 3DL2 binding to HLA-B27 licenses pathogenic $\mathrm{T}$ cell differentiation in spondyloarthritis. Arthritis Rheumatol. (2016) 68:901-14. doi: 10.1002/art.39515

171. Affandi AJ, Silva-Cardoso SC, Garcia S, Leijten EFA, van Kempen TS, Marut W, et al. CXCL4 is a novel inducer of human Th17 cells and correlates with IL-17 and IL-22 in psoriatic arthritis. Eur J Immunol. (2018) 48:522531. doi: 10.1002/eji.201747195

172. He X, Dong Y. Ankylosis progressive homolog upregulation inhibits cell viability and mineralization during fibroblast ossification by regulating the Wnt/ $\beta$-catenin signaling pathway. Mol Med Rep. (2020) 22:455160. doi: $10.3892 / \mathrm{mmr} .2020 .11576$

173. Zou YC, Yang XW, Yuan SG, Zhang P, Ye YL, Li YK. Downregulation of dickkopf- 1 enhances the proliferation and osteogenic potential of fibroblasts isolated from ankylosing spondylitis patients via the Wnt/ $\beta$ catenin signaling pathway in vitro. Connect Tissue Res. (2016) 57:20011. doi: 10.3109/03008207.2015.1127916

174. Xu F, Guanghao C, Liang Y, Jun W, Wei W, Baorong H. Treg-promoted new bone formation through suppressing TH17 by secreting interleukin10 in ankylosing spondylitis. Spine (Phila Pa 1976). (2019) 44:E134955. doi: 10.1097/BRS.0000000000003169

175. Sharif K, Bridgewood C, Dubash S, McGonagle D. Intestinal and enthesis innate immunity in early axial spondyloarthropathy. Rheumatology (Oxford). (2020) 59:iv67-78. doi: 10.1093/rheumatology/keaa408

176. Sibley CH. Autoinflammation and HLA-B27: Beyond Antigen Presentation. Ocul Immunol Inflamm. (2016) 24:4609. doi: 10.1080/09273948.2016.1175641

177. Lamot, L, Bukovac L, Borovecki F, Vlahovicek K, Sumic S, Gotovac K, et al. Clavicular cortical hyperostosis: new autoinflammatory entity or part of the juvenile spondyloarthropathies clinical picture?. Pediatr Rheumatol. (2011) 9:P299. doi: 10.1186/1546-0096-9-S1-P299

178. Chan J, Sari I, Salonen D, Silverberg MS, Haroon N, Inman RD, et al. Prevalence of sacroiliitis in inflammatory bowel disease using a standardized computed tomography scoring system. Arthritis Care Res. (2018) 70:807-10. doi: 10.1002/acr.23323

179. Lamot L, Miler M, Vukojević R, Vidović M, Lamot M, Trutin I, et al. The increased levels of fecal calprotectin in children with active enthesitis related arthritis and MRI signs of sacroiliitis: the results of a single center cross-sectional exploratory study in juvenile idiopathic arthritis patients. Front Med (Lausanne). (2021) 8:650619. doi: 10.3389/fmed.2021. 650619
180. Mielants H, Veys EM, Goethals K, Van der Straeten C, Ackerman C, Goemaere S. Destructive hip lesions in seronegative spondyloarthropathies: relation to gut inflammation. J Rheumatol. (1990) 17:335-40. PMID: 2332855

181. De Vos M, Cuvelier C, Mielants H, Veys E, Barbier F, Elewaut A. Ileocolonoscopy in seronegative spondylarthropathy. Gastroenterology. (1989) 96:339-44. doi: 10.1016/0016-5085(89)91557-6

182. Lee YH, Song GG. Associations between ERAP1 polymorphisms and susceptibility to ankylosing spondylitis: a meta-analysis. Clin Rheumatol. (2016) 35:2009-15. doi: 10.1007/s10067-016-3287-9

183. Harjacek M, Margetić T, Kerhin-Brkljacić V, Martinez N, Grubić Z. HLAB*27/HLA-B*07 in combination with D6S273-134 allele is associated with increased susceptibility to juvenile spondyloarthropathies. Clin Exp Rheumatol. (2008) 26:498-504. PMID: 18578977.

184. Purnamawati K, Ong JA, Deshpande S, Tan WK, Masurkar N, Low $\mathrm{JK}$, et al. The importance of sex stratification in autoimmune disease biomarker research: a systematic review. Front Immunol. (2018) 9:1208. doi: 10.3389/fimmu.2018.01208

185. Park M-C, Kim HW, Lee S-W, Song JJ, Park Y-B. Defective autophagy activity and its association with spinal damage in patients with ankylosing spondylitis. Joint Bone Spine. (2017) 84:583-587. doi: 10.1016/j.jbspin.2016.09.005

186. Sharip A, Kunz J. Understanding the pathogenesis of spondyloarthritis. Biomolecules. (2020) 10:1461. doi: 10.3390/biom10101461

187. Mavropoulos A, Zafiriou E, Simopoulou T, Brotis AG, Liaskos C, Roussaki-Schulze A, et al. Apremilast increases IL-10-producing regulatory $\mathrm{B}$ cells and decreases proinflammatory $\mathrm{T}$ cells and innate cells in psoriatic arthritis and psoriasis. Rheumatology (Oxford). (2019) 58:224050. doi: 10.1093/rheumatology/kez204

188. Wang J, Li Z, Gao L, Qi Y, Zhu H, Qin X. The regulation effect of AMPK in immune related diseases. Sci China Life Sci. (2018) 61:52333. doi: $10.1007 /$ s11427-017-9169-6

189. van Tok MN, Satumtira N, Dorris M, Pots D, Slobodin G, van de Sande MG, et al. Innate immune activation can trigger experimental spondyloarthritis in HLA-B27/Huß2m transgenic rats. Front Immunol. (2017) 8:920. doi: 10.3389/fimmu.2017.00920

190. Zhang Y, Xu S, Li K, Tan K, Liang K, Wang J, et al. mTORC1 inhibits NF-KB/NFATc1 signaling and prevents osteoclast precursor differentiation, in vitro and in mice. J Bone Miner Res. (2017) 32:182940. doi: $10.1002 / \mathrm{jbmr} .3172$

191. Chen S, van Tok MN, Knaup VL, Kraal L, Pots D, Bartels L, et al. mTOR blockade by rapamycin in spondyloarthritis: impact on inflammation and new bone formation in vitro and in vivo. Front Immunol. (2020) 10:2344. doi: 10.3389/fimmu.2019.02344

192. Qin X, Jiang T, Liu S, Tan J, Wu H, Zheng L, et al. Effect of metformin on ossification and inflammation of fibroblasts in ankylosing spondylitis: An in vitro study. J Cell Biochem. (2018) 119:1074-82. doi: 10.1002/jcb.26275

193. Navid F, Layh-Schmitt G, Sikora KA, Cougnoux A, Colbert RA. The role of autophagy in the degradation of misfolded HLA-B27 heavy chains. Arthritis Rheumatol. (2018) 70:746-55. doi: 10.1002/art.40414

194. Weiss PF, Colbert RA. Juvenile spondyloarthritis: a distinct form of juvenile arthritis. Pediatr Clin North Am. (2018) 65:675-90. doi: 10.1016/j.pcl.2018.03.006

195. Diarra D, Stolina M, Polzer K, Zwerina J, Ominsky MS, Dwyer D, et al. Dickkopf-1 is a master regulator of joint remodeling. Nat Med. (2007) 13:156-63. doi: 10.1038/nm1538

196. Anderson GP. Endotyping asthma: new insights into key pathogenic mechanisms in a complex, heterogeneous disease. Lancet. (2008) 372:110719. doi: 10.1016/S0140-6736(08)61452-X

197. Wang Y, Luo J, Wang X, Yang B. Cui L: MicroRNA-199a-5p induced autophagy and inhibits the pathogenesis of ankylosing spondylitis by modulating the mTOR directly targeting ras homolog enriched in brain (Rheb). Cell Physiol Biochem. (2017) 42:2481-91 doi: 10.1159/000480211

198. Burgos-Vargas R, Vázquez-Mellado J, Pacheco-Tena C, HernándezGarduño A, Goycochea-Robles MV. A 26 week randomised, double blind, placebo controlled exploratory study of sulfasalazine in juvenile onset spondyloarthropathies. Ann Rheum Dis. (2002) 61:941-2. doi: 10.1136/ard.61.10.941 
199. Ferrara G, Mastrangelo G, Barone P, La Torre F, Martino S, Pappagallo G, et al. Methotrexate in juvenile idiopathic arthritis: advice and recommendations from the MARAJIA expert consensus meeting. Pediatr Rheumatol Online J. (2018) 16:46. doi: 10.1186/s12969-0180255-8

200. Ceribelli A, Motta F, Vecellio M, Isailovic N, Ciccia F, Selmi C. Clinical trials supporting the role of the IL-17/IL-23 axis in axial spondyloarthritis. Front Immunol. (2021) 12:622770. doi: 10.3389/fimmu.2021.6 22770

201. van der Heijde D, Deodhar A, Wei JC, Drescher E, Fleishaker D, Hendrikx T, et al. Tofacitinib in patients with ankylosing spondylitis: a phase II, 16-week, randomised, placebo-controlled, dose-ranging study. Ann Rheum Dis. (2017) 76:1340-7. doi: 10.1136/annrheumdis-2016-2 10322

202. de Vlam K, Ogdie A, Bushmakin AG, Cappelleri JC, Fleischmann R, Taylor PC, et al. Median time to pain improvement and the impact of baseline pain severity on pain response in patients with psoriatic arthritis treated with tofacitinib. RMD Open. (2021) 7:e001609. doi: 10.1136/rmdopen-2021-001609

203. Maben Z, Arya R, Rane D, An WF, Metkar S, Hickey M, et al. Discovery of selective inhibitors of endoplasmic reticulum aminopeptidase 1. J Med Chem. (2020) 63:103-21. doi: 10.1021/acs.jmedchem.9b 00293

204. Liu S, Cui Y, Zhang X. Molecular mechanisms and clinical studies of iguratimod for the treatment of ankylosing spondylitis. Clin Rheumatol. (2021) 40:25-32. doi: 10.1007/s10067-020-05 207-z

205. Bilsborrow JB, Doherty E, Tilstam PV, Bucala R. Macrophage migration inhibitory factor (MIF) as a therapeutic target for rheumatoid arthritis and systemic lupus erythematosus. Expert Opin Ther Targets. (2019) 23:733-44. doi: 10.1080/14728222.2019.16 56718

206. Osipyan A, Chen D, Dekker FJ. Epigenetic regulation in macrophage migration inhibitory factor (MIF)-mediated signaling in cancer and inflammation. Drug Discov Today. (2021) 26:1728-34. doi: 10.1016/j.drudis.2021.03.012
207. Vojinovic J, Damjanov N. HDAC inhibition in rheumatoid arthritis and juvenile idiopathic arthritis. Mol Med. (2011) 17:397-403. doi: 10.2119/molmed.2011.00030

208. Rigby WF, Mease PJ, Olech E, Ashby M, Tole S. Safety of rituximab in combination with other biologic disease-modifying antirheumatic drugs in rheumatoid arthritis: an open-label study. J Rheumatol. (2013) 40:599604. doi: 10.3899/jrheum.120924

209. Ferrari M, Onuoha SC, Fossati-Jimack L, Nerviani A, Alves PL, Pagani $\mathrm{S}$, et al. Novel bispecific antibody for synovial-specific target delivery of anti-TNF therapy in rheumatoid arthritis. Front Immunol. (2021) 12:640070. doi: 10.3389/fimmu.2021.640070

210. Hou X, Qu H, Zhang S, Qi X, Hakonarson H, Xia Q, Li J. The Multi-omics architecture of juvenile idiopathic arthritis. Cells. (2020) 9:2301. doi: 10.3390/cells9102301

211. Nigrovic PA, Colbert RA, Holers VM, Ozen S, Ruperto N, Thompson SD, et al. Biological classification of childhood arthritis: roadmap to a molecular nomenclature. Nat Rev Rheumatol. (2021) 17:25769. doi: 10.1038/s41584-021-00590-6

Conflict of Interest: The author declares that the research was conducted in the absence of any commercial or financial relationships that could be construed as a potential conflict of interest.

Publisher's Note: All claims expressed in this article are solely those of the authors and do not necessarily represent those of their affiliated organizations, or those of the publisher, the editors and the reviewers. Any product that may be evaluated in this article, or claim that may be made by its manufacturer, is not guaranteed or endorsed by the publisher.

Copyright $(02021$ Harjacek. This is an open-access article distributed under the terms of the Creative Commons Attribution License (CC BY). The use, distribution or reproduction in other forums is permitted, provided the original author(s) and the copyright owner(s) are credited and that the original publication in this journal is cited, in accordance with accepted academic practice. No use, distribution or reproduction is permitted which does not comply with these terms. 